\title{
Reglas y Advertencias Generales de Pablo Minguet (1754 y 1774): Estudio de sus diferentes ediciones y análisis de las pautas para la interpretación de la guitarra
}

\author{
Pablo Minguet's Reglas y Advertencias Generales (1754 and 1774): \\ Study of the differente editions and analysis of the guidelines for \\ an interpretation of the guitar
}

\author{
Sakira Ventura Quintana \\ Universidad de Castilla-La Mancha \\ sakiraventuraq@gmail.com \\ ORCID iD: https://orcid.org// 0000-0001-7294-9213
}

\section{RESUMEN}

Dentro del corpus tan variado de publicaciones del editor catalán Pablo Minguet, destaca el tratado pedagógico-musical titulado Reglas y Advertencias Generales que enseñan el modo de tañer todos los instrumentos mejores, y mas usuales, como son la Guitarra, Tiple, Vandola, Cythara, Clavictordio, Organo, Harpa, Psalterio, Bandurria, Violin, Flauta Travesera, Flauta Dulce y la Flautilla. Este tratado formado por cuadernillos individuales fue concebido para aprender a tocar determinados instrumentos e interpretar su repertorio sin necesidad de maestro, pero para la Musicología actual supone una importante fuente de estudio y análisis de la panorámica organológica del Madrid a mediados del siglo XVIII.

Palabras clave: guitarra, Madrid, Pablo Minguet, pedagogía musical, tratadística. 


\section{SAKIRA VENTURA QUINTANA}

\section{Abstract}

Within the corpus of publications of the Catalan publisher Pablo Minguet, stands out the pedagogical-musical treatise entitled Reglas y Advertencias Generales que enseñan el modo de tañer todos los instrumentos mejores, y mas usuales, como son la Guitarra, Tiple, Vandola, Cythara, Clavictordio, Organo, Harpa, Psalterio, Bandurria, Violin, Flauta Travesera, Flauta Dulce y la Flautilla. This treatise formed by individual booklets was conceived to learn to play certain instruments and to interpret their repertoire without the need of a teacher, but for today's Musicology it is an important source of study and analysis of the organological panorama of Madrid in the middle of the 18th century.

Key Words: guitar, Madrid, musical pedagogy, Pablo Minguet, tratadistic.

Ventura Quintana, S. (2020). Reglas y Advertencias Generales de Pablo Minguet (1754 y 1774): Estudio de sus diferentes ediciones y análisis de las pautas para la interpretación de la guitarra. Cuadernos de Investigación Musical, 9, pp. 57-83.

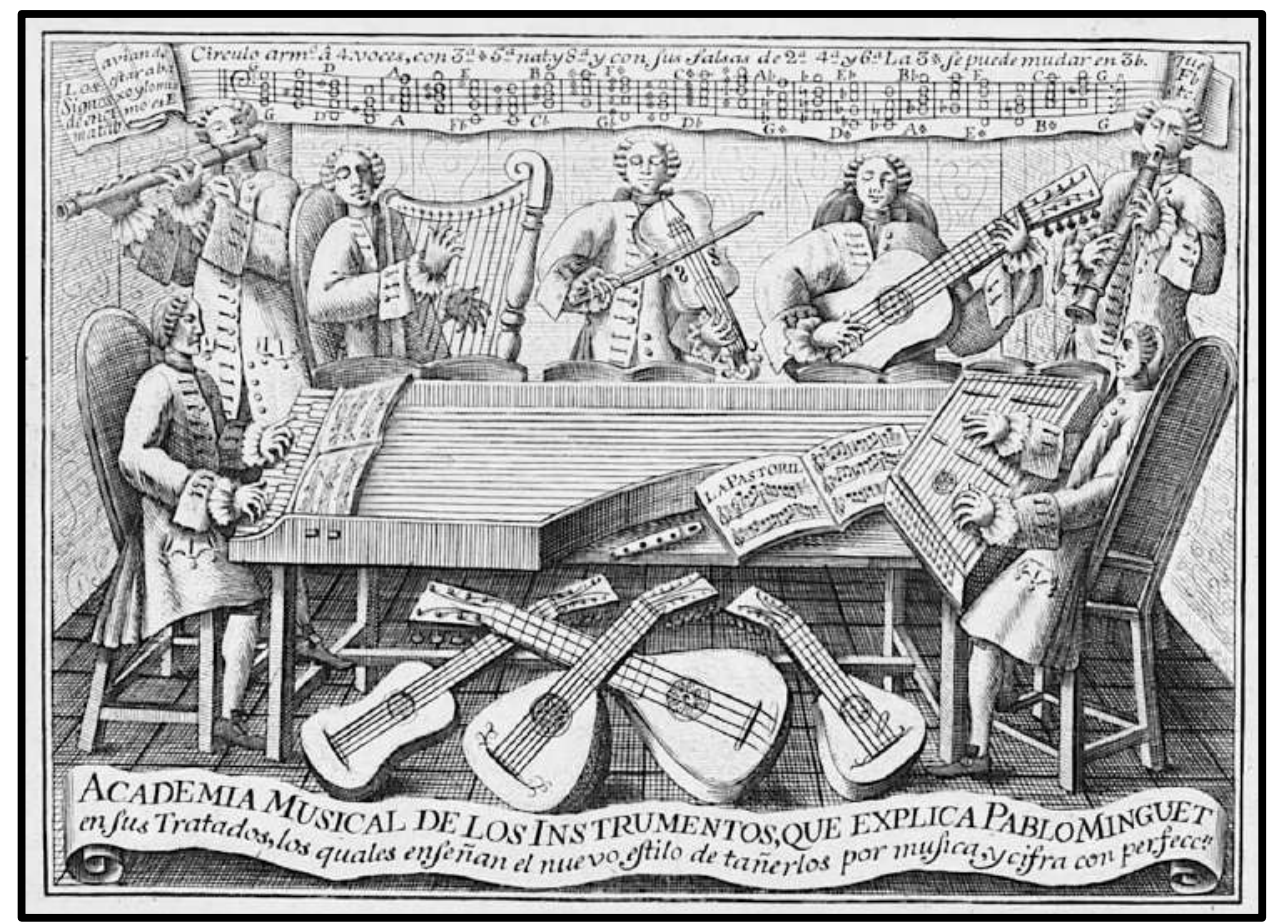

Fig. 1: Frontispicio tratado Reglas y Advertencias Generales de Pablo Minguet. 
Reglas y AdVERTENCIAS Generales de Pablo Minguet (1754 y 1774): Estudio DE SUS

DIFERENTES EDICIONES Y ANÁLISIS DE LAS PAUTAS PARA LA INTERPRETACIÓN DE LA GUITARRA

\section{INTRODUCCIÓN}

Pablo Minguet (*Barcelona, 1715; †Madrid, 1778c) fue el autor del tratado pedagógico-musical Reglas y Advertencias generales dedicado al aprendizaje de la guitarra, tiple, bandola, cítara, clavicordio, órgano, arpa, salterio, bandurria, violín, flauta travesera, flauta dulce y flautilla y la interpretación del repertorio de los mencionados instrumentos. Debido a la amplia variedad temática de sus publicaciones —entre las que se encuentran escritos tan diversos como planos, calendarios, origen y reglas del ajedrez, grabados de santos y manuales de magia—, no es de extrañar que teóricos como Rafael Mitjana (Mitjana, 1993, p. 296) y Francisco José León Tello (León Tello, 1974, p. 740) lo calificaran como un "autor curioso" o, en palabras de Antonio Martín Moreno (Martín Moreno, 1985, p. 303), un "avispado editor"; ya que esta multiplicidad de materias impresas manifiesta su habilidad para cubrir las diferentes demandas del mercado y permite suponer que se trataba de una persona con un amplio abanico de conocimientos e intereses.

Editor, teórico musical y "grabador de sellos, láminas, firmas y otras cosas" — como él mismo se define en algunas portadas de los cuadernillos de su tratado—, Pablo Minguet se formó de manera autodidacta (Michel, 1967, p. 349) y estuvo en activo en Madrid “de 1733 hasta 1775" (Sanhuesa, 2000, p. 588). De igual modo, y como veremos más adelante, en diversas portadas de los cuadernos instructivos también especifica que su propia imprenta se situaba "frente a la Cárcel de la Corte, encima de la Botica de Provincia".

En su amplio recorrido como empresario en el ámbito musical se debe precisar que fue un gran recopilador de las obras teóricas pedagógicas de música del momento aunque no mencione todas las fuentes que utiliza en sus trabajos- e incluso "pudo haber compuesto algunos de los ejemplos musicales de su tratado [Reglas y Advertencias]"2.

\section{REGLAS Y ADVERTENCIAS}

El nacimiento de nuevos espacios para la formación e interpretación musical en el siglo XVIII amplió exponencialmente el público interesado en participar de dicho arte, lo que hizo necesario la publicación de diferentes escritos de instrucción que facilitaran ese proceso. Pablo Minguet contribuyó con este escrito a la posibilidad de aprender a tocar los "instrumentos mejores y más usuales" del momento e interpretar su repertorio sin necesidad de maestro, práctica que ya había llevado a cabo Gaspar Sanz en su tratado Instrucción de música sobre la guitarra española (Sanz, 1674, p. 67), aunque Minguet - y otros antes que él, como Lucas Ruiz de Ribayaz (Ruiz de Ribayaz, 1677, p. 32) - criticara estas referencias

\footnotetext{
${ }^{1}$ Dirección proporcionada por Pablo Minguet en la portada de la parte de guitarra, tiple y vandola de su tratado.

2 "Einige seiner Musikbeispiele hat er möglicherweise selbst komponiert" (Finscher, 2004, p. 246). Traducción propia.
} 


\section{SAKIRA VENTURA QUINTANA}

anteriores por ofrecer directrices que, bajo su criterio, eran demasiado complejas para los aprendices ${ }^{3}$ :

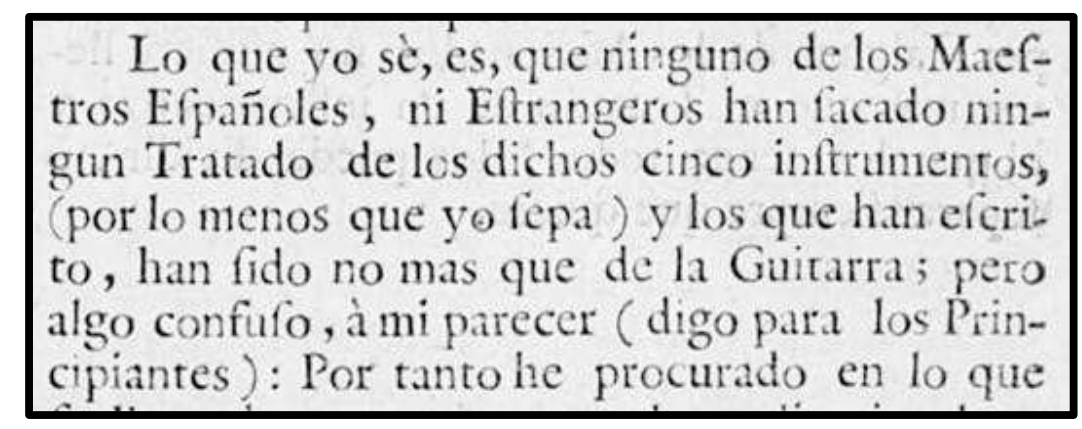

Fig. 2: «Prólogo al lector aficionado», Reglas y Advertencias (1754)

Lothar Siemens definió el tratado instructivo que nos ocupa en este artículo como una "más mencionada que estudiada obra" (Siemens, 1988, p. 6). Si bien los escritos de Pablo Minguet que versan sobre danza ${ }^{4}$ han obtenido su justa trascendencia dentro de la historia de la teoría musical española por haber difundido las danzas de origen francés en España - tal y como Santiago de Murcia hizo previamente con los arreglos de danzas para guitarra-, el tratado Reglas y Advertencias con sus diversas ediciones ha pasado desapercibido a través de los años por ofrecer, sobre todo, conocimientos que expusieron otros autores antes que él. Sin embargo, el valor de este tratado trasciende del de la mera recopilación de pautas metodológicas de grandes teóricos como Gaspar Sanz, sino que Minguet aporta reglas muy precisas para aprender a tocar determinados instrumentos e interpretar ejemplos musicales que no están contemplados en obras anteriores a su tratado —y que podrían ser de su propia autoría - y, por otro lado, ofrece instrucción para instrumentos que hasta ese momento no tenían dedicado ningún tratado pedagógico.

Así pues, desde las influencias que el propio Minguet recibió para elaborar su tratado pedagógico-musical, hasta los autores que utilizaron el contenido de esta obra para crear sus propios manuales instructivos, todos ellos conforman una gran suma de escritos de formación que se complementan y arrojan luz tanto sobre los diferentes atributos de los instrumentos que se ofertan, como sobre el repertorio que los compositores y compositoras les han destinado.

\footnotetext{
${ }^{3}$ La figura 1, junto con las figuras 3, 4, 7, 9, 12, 16, 17, 18, 19, 21, 23, 25, 26, 28, 30, 33, 34 y 36 pertenecen a la edición global de 1754 del tratado Reglas y Advertencias Generales de Pablo Minguet, custodiada por la Biblioteca Nacional de España con la signatura M/894.

${ }^{4}$ Quadernillo curioso de veinte contradanzas nuevas, escritas de todas quantas maneras se han inventado hasta abora (1733); Arte de danzar a la francesa (1755); Breve tratado de los passos del danzar a la española (1764); Breve explicación de diferentes danzas y contradanzas (sin fecha); Explicación y demostración de los bayles que más se usan en las cortes de Europa (sin fecha); El noble arte de danzar a la francesa y española adorado con XL láminas (sin fecha).
} 
Reglas y AdVERTENCIAS Generales de Pablo Minguet (1754 y 1774): Estudio DE SUS

DIFERENTES EDICIONES Y ANÁLISIS DE LAS PAUTAS PARA LA INTERPRETACIÓN DE LA GUITARRA

\section{Particularidades del TRatado}

Aunque se publicó una edición parcial del tratado en 1753 que contenía los cuadernillos de guitarra, tiple, vandola, bandurria y violín -información recogida en la crónica del periódico La Gaceta del 05/06/1753-, las dos fuentes principales que he utilizado para este artículo son, por un lado, la edición global de 1754 custodiada por la Biblioteca Nacional de España $(\boldsymbol{E}-\mathrm{Mn})$ bajo la signatura M/894 y, por otro lado, la reedición global de 1774 custodiada por la Biblioteca de Catalunya $(\boldsymbol{E}$-Bn $)$ con la referencia Palau 170459.

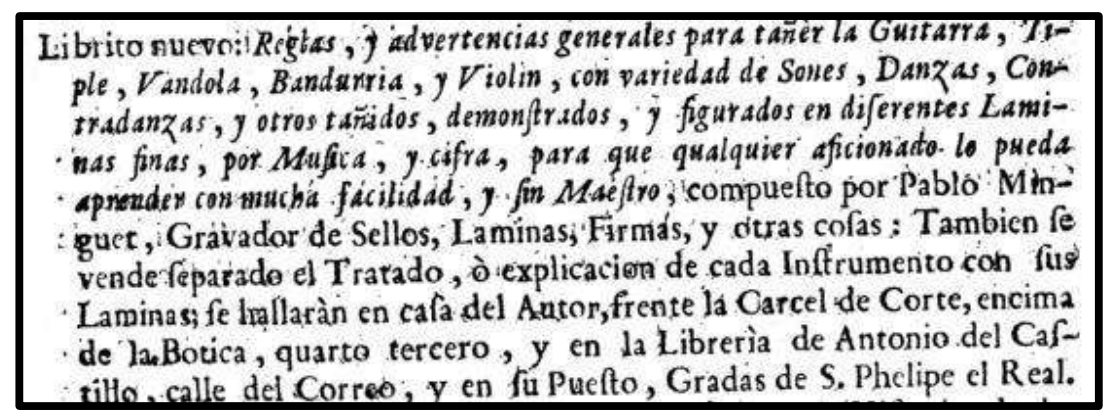

Fig. 3: 05/06/1753, La Gaceta, n. ${ }^{\circ}$ 23, p. 184.

(Agencia Estatal Boletín Oficial del Estado).

\subsection{BREVE DESCRIPCIÓN ESTÉTICA}

Después de las hojas en blanco o de cortesía y del elaborado frontispicio de título Academia musical de los instrumentos que explica Pablo Minguet ${ }^{5}$ (véase primera imagen en página 1), aparecen los folios preliminares que los autores debían poner de manera obligatoria a partir de los Reyes Católicos. Servían para regular los factores económicos de su producción y para controlar la difusión de las ideas relativas a la fe y buenas costumbres ${ }^{6}$. Se colocaban al principio del libro, entre la portada y el desarrollo formal de la obra. En función del contenido temático podían clasificarse en folios preliminares de carácter literario o civil ${ }^{7}$.

A continuación, el tratado ofrece una portada general y otra para cada cuadernillo independiente que presentará cambios en función de la edición. En la primera publicación, datada en 1754, observamos la variante de portada que presenta el modo de impresión con

\footnotetext{
${ }^{5}$ En este frontispicio aparecen todos los instrumentos que el autor trata en Reglas y Advertencias a excepción del órgano.

6 Tanto en la Aprobación de Gaspar Álvarez, como en la Licencia del ordinario de Don Thomàs de Naxera y en la Aprobación de Don Juan Marchena aparecen reflejados estos dos aspectos aceptados para la publicación de Reglas y Advertencias.

${ }^{7}$ La edición de 1754 contiene folios preliminares de ambas temáticas, a diferencia de su reedición en 1774, que solo contiene los folios preliminares de carácter literario con el mismo contenido que en la impresión de 1754.
} 


\section{SAKIRA VENTURA QUINTANA}

privilegio, el nombre del impresor Joaquín Ibarra en versalitas y no especifica la fecha de impresión:

\section{Con Privilegio. En Madrid, por Joaguin I DarRa, calle de las Urofas.}

Fig. 4: Portada del cuadernillo de guitarra, tiple y vandola (1754)

La segunda variante de portada contiene el modo de impresión con licencia, el nombre del impresor con la primera letra de su nombre y de su apellido en mayúscula y el resto de letras en minúscula, y adjuntando la fecha de impresión:

Con Licencia. En Madrid, en la Imprenta de Joachin Ibarra, Calle de las Urofas. Año de 17.54:

Fig. 5: Portada del cuadernillo del psalterio (1754)

En la segunda edición de Reglas y Advertencias se dan muchos tipos de portadas. De hecho, solo una de ellas especifica que se ha imprimido en la imprenta del propio Pablo Minguet — situada enfrente de la Cárcel de Corte $^{8}$, encima de la Botica (Madrid) en 1774_, y es la portada del primer cuadernillo que vamos a tratar en este escrito. Presenta licencia, especifica que la impresión se ha realizado en la imprenta del autor en el año 1774 y, además, hace publicidad del resto de obras que también se podían comprar allí:

\section{Con licencia: En Madrid, en la Imprenta del dicho Autor, año de 1774. Vive en- frente de la Carcel de Corte, encima de la Borica, donde se hallarán éscas, y rodas sus Obras muy uriles para toda clase de Personas.}

Fig. 6: Portada del cuadernillo de guitarra, tiple y vandola (1774).

El segundo cuadernillo titulado para acompañar sobre la parte con la guitarra, clavicordio, órgano, arpa, cithara, ò qualquier otro instrumento muestra licencia, el nombre del impresor (Joaquín Ibarra) en versalitas y no especifica la fecha de impresión:

\footnotetext{
${ }^{8}$ La Cárcel de la Corte —actual Palacio de Santa Cruz y sede del Ministerio de Asuntos Exteriores y Cooperación español— se situaba en la Plaza Mayor de Madrid.

${ }^{9}$ La figura 5, junto con las figuras 6, 7, 8, 9, 10, 11, 13, 14, 24, 27, 29, 30, 32, 35 y 38 pertenecen a la edición global de 1774 del tratado Reglas y Advertencias Generales de Pablo Minguet, custodiada por la Biblioteca de Catalunya con la referencia Palau 170459.
} 


\section{Con Licencia. En Madrid, por Joachin I I Arra, calle de las Urofas.}

Fig. 7: Portada del cuadernillo para acompañar sobre la parte con la guitarra, clavicordio, etc. (1774).

El tercer cuadernillo — dedicado al salterio- tiene licencia, el nombre de Joaquín Ibarra en mayúsculas y minúsculas y el año 1754:

\section{Con Licencia. En Madrid, en la Imprenta de Joachin Ibarra, Calle de las Urofas. Año de I754:}

Fig. 8: Portada del cuadernillo de psalterio (1774, con licencia de 1754).

El cuarto y quinto cuadernillo, para bandurria y violín respectivamente, ofrecen el mismo formato de portada: ambos presentan privilegio, el autor aparece en versalitas y no contiene fecha:

\section{Con Privilegio. En Madrid, por Joacuin Ibarra, Calle de las Urofas.}

Fig. 9: Portada del cuadernillo de bandurria (1774).

El sexto y último cuadernillo, escrito para flauta travesera, flauta dulce y la flautilla, incluyen licencia, el nombre del autor en mayúsculas y minúsculas y el año (1754):

\section{Con Licencia. En Madrid, en la Imprenta de Joachin Ibarra, Calle de las Urofas.} Año de 1754 .

Fig. 10: Portada del cuadernillo de flauta travesera, flauta dulce y la flantilla (1774, con licencia de 1754).

En cuanto a cómo está distribuida la información en los cuadernillos, Pablo Minguet la reparte en dos columnas, independientemente de la edición del tratado. Aunque el autor no añade foliación ni paginación en ninguna de las dos ediciones porque —como él mismo 


\section{SAKIRA VENTURA QUINTANA}

reconoce - los cuadernillos del tratado también podían venderse por separado ${ }^{10}$, al finalizar la segunda columna de cada página encontramos un reclamo de la primera sílaba o de la primera palabra completa de la página siguiente.

Esta diversidad en las portadas de la segunda edición del tratado sugiere que Pablo Minguet decidió reutilizar material de la primera edición: concretamente, aquellos cuadernillos impresos por Joaquín Ibarra. Por ello, las diferencias más sustanciales de contenido - que no las únicas - que encontramos entre la primera edición del tratado y la segunda se hallan en el primer cuadernillo, aquel que está datado en el año 1774 y que imprimió en su propia imprenta.

Más aún, es pertinente mencionar las ornamentaciones gráficas que Minguet añade en su reedición de 1774, ya que no las usa anteriormente. Estos adornos los utiliza para separar secciones en el cuadernillo que nos atañe, el de la guitarra. El primer ornamento que aparece es una franja con arabescos para dividir las reglas para tocar de rasgueado de las siguientes para puntear:

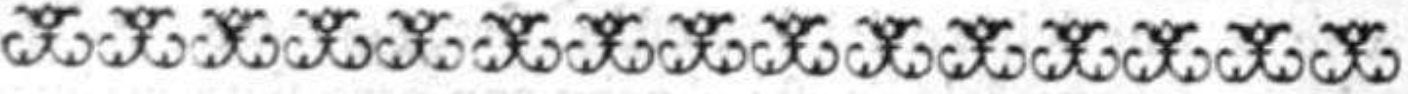

Fig. 11: Cuadernillo para acompañar sobre la parte con la guitarra, etc.

Antes de comenzar sus Advertencias para los principiantes y aficionados a la guitarra también introduce una franja, pero esta vez entrelazada con una cruz en el centro:

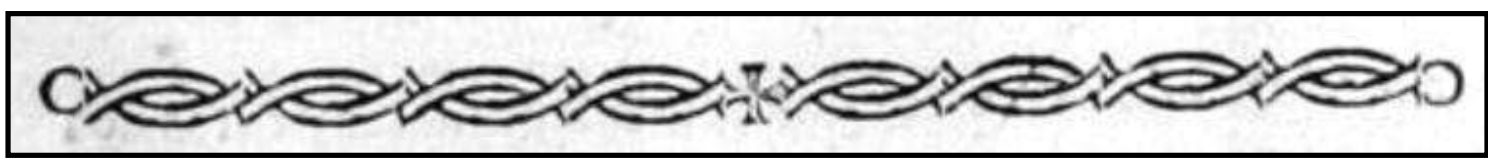

Fig. 12: Cuadernillo para acompañar sobre la parte con la guitarra, etc.

Otro aspecto que debe ser resaltado es la técnica de impresión que Minguet utiliza en algunos de los títulos que inician los diferentes apartados del tratado. Esta técnica se denomina base de lámpara y es propia del Renacimiento, dos siglos anterior a su producción. Este tipo de impresión se caracteriza por escribir el título o el último párrafo formando un triángulo invertido (Hochuli, 2005, p. 34):

10 "Aunque estos cuadernillos podian adquirirse de forma individual, invitaban a ser coleccionado como una serie coberente" (Leza, 2014, p. 458). 


\section{EXPLICACION DE LA LAMINA SEXTA, cn la qual eftin las Efcalas de Don Santiago de Murcia, para acompaniar la parte con la Guitarra.}

Fig. 13: Cuadernillo de la guitarra, tiple y vandola (1754).

En cuanto a su estructura interna, se observa que es un tratado con partes bien diferenciadas ya que está constituido por cuadernillos independientes, cada uno de ellos con su propia portada descriptiva. La primera diferencia entre ambas ediciones es la falta de Folios preliminares de carácter civil y el Prólogo al lector aficionado en la edición de 1774, por lo que el cuerpo del texto va a continuación de la portada del primer cuadernillo.

Cuatro de los seis cuadernos en ambas ediciones siguen una estructura interna similar, presentando una enumeración de reglas para la interpretación del instrumento particular. También en sendas ediciones, Minguet incluye un apartado de Nota y otro de "Advertencia" al finalizar los cuadernillos primero, cuarto y quinto. Por último, se puede apreciar algunas diferencias estructurales entre ediciones como el cambio de orden de láminas o la introducción de alguna de ellas en la reedición de 1774.

\subsection{HERENCIAS RECIBIDAS}

A raíz del incipiente interés que despertó la música desde sus múltiples perspectivas en el siglo XVIII, se dio un auge en la literatura musical — tanto en cantidad como en variedad - que pretendía cubrir la creciente demanda del mercado. Asimismo, aparte de las diversas polémicas ${ }^{11}$ que se abordaron durante este periodo, hallamos diferentes campos temáticos dentro de las publicaciones musicales dieciochescas.

El primer grupo de tratados está formado por los que versan sobre la teoría del canto llano. Desde las obras de Antonio de la Cruz Brocarte ${ }^{12}$ y Jorge Guzmán ${ }^{13}$ hasta el escrito de Vicente Pérez ${ }^{14}$ en 1799, se sucedieron innumerables escritos de la citada materia. También se deben mencionar los tratados de Pedro de Ulloa ${ }^{15}$ y el de Pablo Nassarre ${ }^{16}$, así como todos los que se refieren a la danza, entre los que podemos destacar dos obras de Pablo Minguet: El noble arte de danzar a la francesa ${ }^{17}$ y Breve tratado de los pasos del danzar a la

\footnotetext{
${ }^{11}$ Derivadas de "la nueva actitud hacia la música y a la influencia de la música teatral" (Martín Moreno, 1985, p. 439).

12 Cruz Brocarte, A. (1707). Medula de la música teórica cuya inspección manifiesta claramente la ejecución de la práctica en división de cuatro discursos. Salamanca.

13 Guzmán, J. (1709). Curiosidades del cantollano, sacadas de las obras del Reverendo don Pedro Cerone de Bérgamo y de otros autores. Madrid: Imprenta de Música.

14 Pérez Martínez, V. (1799). Prontuario del canto llano gregoriano. Madrid: Pedro Julián Pereyra.

${ }^{15}$ Ulloa, P. (1717). Música universal o principios universales de la música. Madrid: Bernardo Peralta.

${ }^{16}$ Nassarre, P. (1724). Escuela música según la práctica moderna. Zaragoza: Herederos de Diego de Larumbe.

${ }^{17}$ Minguet, P. (1755). El noble arte de danzar a la francesa. Madrid: Pablo Minguet.
} 


\section{SAKIRA VENTURA QUINTANA}

española ${ }^{18}$. Paralelamente se gestaron los métodos de instrucción musical dirigidos al reciente público amateur. De estos últimos me centraré en los dedicados a la guitarra pues es el cuadernillo de Reglas y Advertencias que pretendo examinar en este artículo; cuaderno que, por otro lado, será el que presente más cambios y adiciones en la reedición de 1774. Por consiguiente, la finalidad de este escrito será presentar cuáles eran las pautas que guiaban el aprendizaje e interpretación de la guitarra en el Madrid de mediados del siglo XVIII a través de la óptica de este tratado instructivo.

Así pues, en un barrido cronológico por los tratados pedagógicos de guitarra que han servido de influencia para el método de Minguet, el primero al que se debe hacer mención es Guitarra española y vandola en dos maneras de guitarra, castellana y cathalana de cinco órdenes, la qual enseña de templar y tañer rasgado de Joan Carles Amat ${ }^{19}$, mucho anterior al marco temporal que envuelve la publicación de Reglas y Advertencias. Este tratado supondrá el inicio de un gran legado de escritos para la instrucción de guitarra que lo tomarán como referencia y que, debido al éxito tan extraordinario que obtuvo en toda Europa, "se vio obligado a publicar varias ediciones en años posteriores" (Ramos Altamira, 2005, p. 29).

El siguiente tratado de este recorrido lo menciona Pablo Minguet como una de sus fuentes en el Índice y explicación de toda la obra de ambas ediciones de Reglas y Advertencias. Se trata de Instrucción de música sobre la guitarra española y método de sus primeros rudimentos hasta tañerla con destreza de Gaspar Sanz. Esta obra —nacida unas décadas antes del tratado de Minguet - supone el método de enseñanza de guitarra más completo del período no solo por el método instructivo que contiene, sino también por los ejemplos musicales compuestos por el propio Sanz.

Otra de las influencias de Pablo Minguet fue el tratado Luz y norte musical del guitarrista, compositor y sacerdote burgalés Lucas Ruiz de Ribayaz. Este tratado pedagógico contiene pautas detalladas para la instrucción de la guitarra barroca y el arpa, un apéndice con obras para ambos instrumentos y capítulos sobre teoría musical que "son menos interesantes porque repiten la teoría común" (León Tello, 1974, p. 697). Las influencias de este autor en Reglas y Advertencias son relevantes pues forman parte de la aportación personal del propio Ribayaz y no de la herencia recibida de Gaspar Sanz.

La segunda fuente que cita Minguet en su tratado es Santiago de Murcia — profesor de guitarra de María Luisa Gabriela de Saboya- y su Resumen de acompañar la parte con la guitarra. Este método, dividido en dos partes, es valioso por todos los ejemplos musicales en diferentes metros y modos, de donde resulta que su mayor relevancia sea la predominancia de repertorio francés, justificada "con el contexto cultural y politico en el que se produjo" (Vera, 2008, p. 597).

Estos métodos gozaron de una gran difusión y se les ha considerado la mayor referencia en esta temática por su practicidad y utilidad en la instrucción de la guitarra. No es de extrañar, por tanto, que fueran el primer punto de partida para que Minguet elaborara esta obra.

\footnotetext{
${ }_{18}^{18}$ Minguet, P. (1764). Breve tratado de los pasos del danzar a la española. Madrid: imprenta del autor.

19 Amat, J.C. (1596). Guitarra española y vandola en dos maneras de guitarra, castellana y cathalana de cinco órdenes, la qual enseña de templar y tañer rasgado. Barcelona: Gabriel Bro.
} 
Reglas y AdVERTENCIAS GENERALES DE Pablo Minguet (1754 Y 1774): Estudio De SUS

DIFERENTES EDICIONES Y ANÁLISIS DE LAS PAUTAS PARA LA INTERPRETACIÓN DE LA GUITARRA

\section{CUADERNILLO DE LA GUITARRA, TIPLE, Y VANDOLA}

Este cuadernillo sufrió una actualización en la reedición del tratado en 1774 que asevera el auge de este instrumento en las últimas décadas del siglo XVIII, de donde resulta que en 1799 vieran la luz una serie de métodos para guitarra ${ }^{20}$ que, además, manifestaron su inminente carácter solístico. Por tanto, exponer aquellas diferencias entre ediciones reflejará los cambios y modificaciones en la interpretación de la guitarra transcurridos veinte años desde la primera impresión de Reglas y Advertencias hasta la siguiente. El propio Pablo Minguet informó de esta revisión en la portada del cuadernillo:

\section{COMPUESTAS, $r$ CORREGIDAS EN ESTA ULTIMA IMPRESION POR PABLO} Minguet y Yrol, Gravador de Sellos, Laminas, Firmas, y otras cosas.

Fig. 14: Portada del cuadernillo de la guitarra, tiple, y vandola (1774).

La primera aportación de Minguet al deseoso de tañer la guitarra es una descripción del instrumento y de sus partes, regla expuesta tanto en la edición de 1754 como en la de 1774 y que está basada en la primera parte del capitulo 1 del tratado Luz y norte musical de Ruiz de Ribayaz ${ }^{21}$. En él, Minguet parte de la descripción de la ceja y de los trastes, pero omite la referencia de Ribayaz sobre los órdenes de la guitarra:
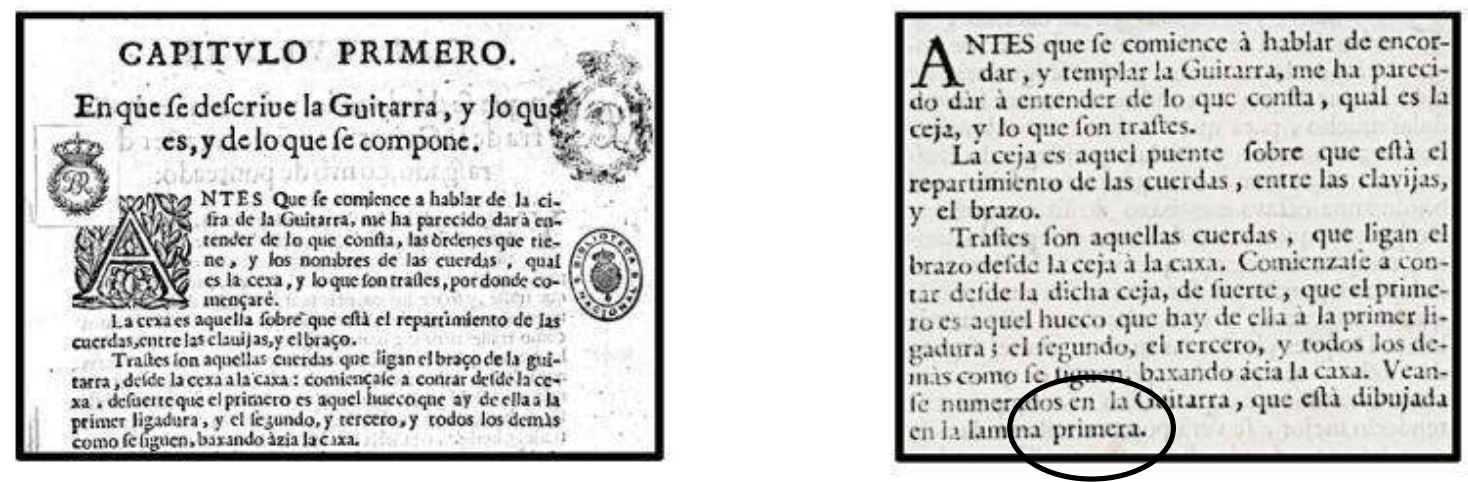

Fig. 15: Comparativa regla primera (Ribayaz, 1677 - Minguet, 1774).

\footnotetext{
20 Abreu, A. (1799). Escuela para tocar con perfección la guitarra. Salamanca: Imprenta de la calle del Prior; Fernandiere, F. (1799). Arte de tocar la guitarra española por música. Madrid: Pantaleón Aznar; García Rubio, J.M. (1799). Arte, reglas y escalas armónicas para aprehender a templar y puntear la Guitarra Española de seis órdenes según el estilo moderno; Moretti, F. (1799). Principios para tocar la guitarra de seis órdenes, precedido de los elementos generales de la música. Madrid: Gabriel de Sancha y Vargas y Guzmán, J.A. (1799). Explicación de la guitarra de rasgueado, punteado y haciendo la parte de el baxo repartida en tres tratados por su orden. Cádiz.

${ }^{21}$ La figura 14 pertenece al tratado Luгy Norte Musical de Lucas Ruíz de Ribayaz, custodiado por la Biblioteca Nacional de España bajo la signatura R/9402.
} 


\section{SAKIRA VENTURA QUINTANA}

La única diferencia que aparece en esta primera regla entre ambas ediciones de Reglas y Advertencias es que en la reedición de 1774 especifica de forma precisa las láminas a las que hay que recurrir a modo de ejemplo. Como avanzábamos anteriormente, este punto heredado de Ribayaz pertenece a la aportación personal del propio autor y no a influencias anteriores recibidas.

La regla segunda De encordar la guitarra y lo que conduce à este efecto está copiada en su totalidad en la edición de 1754 y, de manera parcial en la edición de 1774, de la regla primera del tratado Instrucción de música sobre la guitarra española de Gaspar Sanz ${ }^{22}$. En ella, Sanz - y por ende, Pablo Minguet- establece la diferencia entre colocar las cuerdas al estilo italiano, esto es, sin el uso de bordones para puntear "con primor, y dulcura" (Sanz, 1674, p. 1), y encordar al estilo español: "para hazer musica ruidosa” (Sanz, 1674, p. 1). Además, Minguet también incluye en su Reglas y Advertencias el consejo para la conservación de las cuerdas que ofrece Gaspar Sanz:

Las cuerdas para que estèn en su perfeccion, y no se gasten, se deven conservar en una cagilla, ò cañon de oja de lata, ò sino, en una vadanilla con azeite de almendras dulces; y si no tuvieres comodidad para esso, guardalas en un pucherillo emberniçado bien cubierto, y si fuere nuevo, es mucho mejor, $y$ assi tendràs las cuerdas frescas (Sanz, 1674, p. 2).
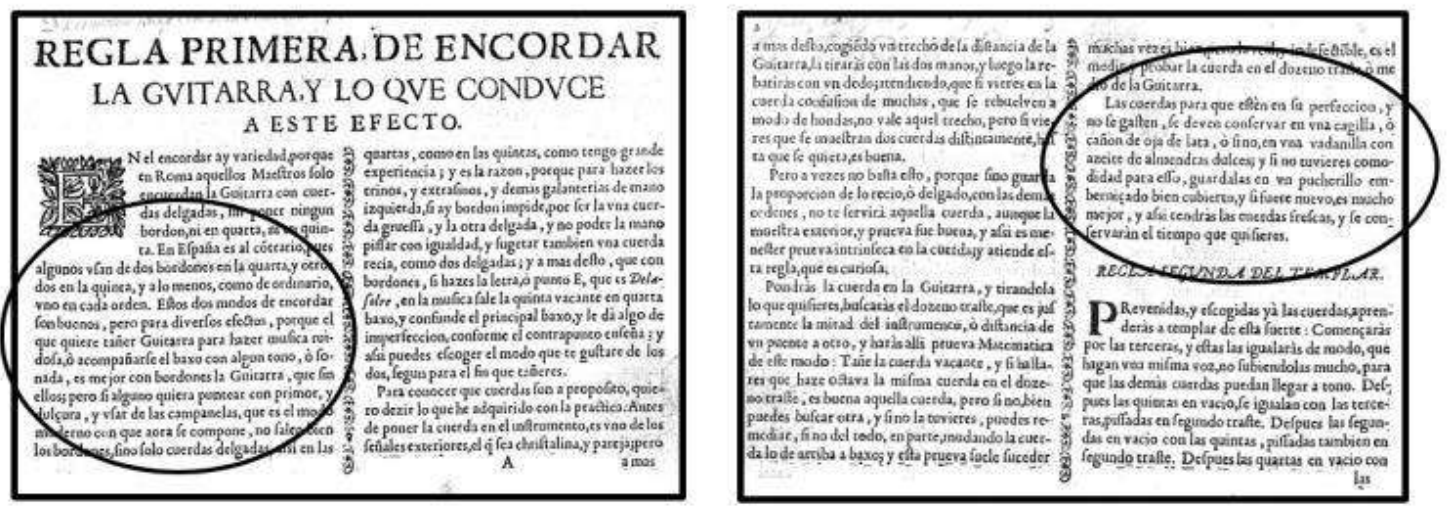

Fig. 16: Regla primera de Gaspar Sanz (1674).

22 La figura 15, junto con la 20 y la 22, pertenecen al tratado Instrucción de música sobre la guitarra española de Gaspar Sanz, custodiado por la Biblioteca Nacional de España bajo la signatura M/160. 

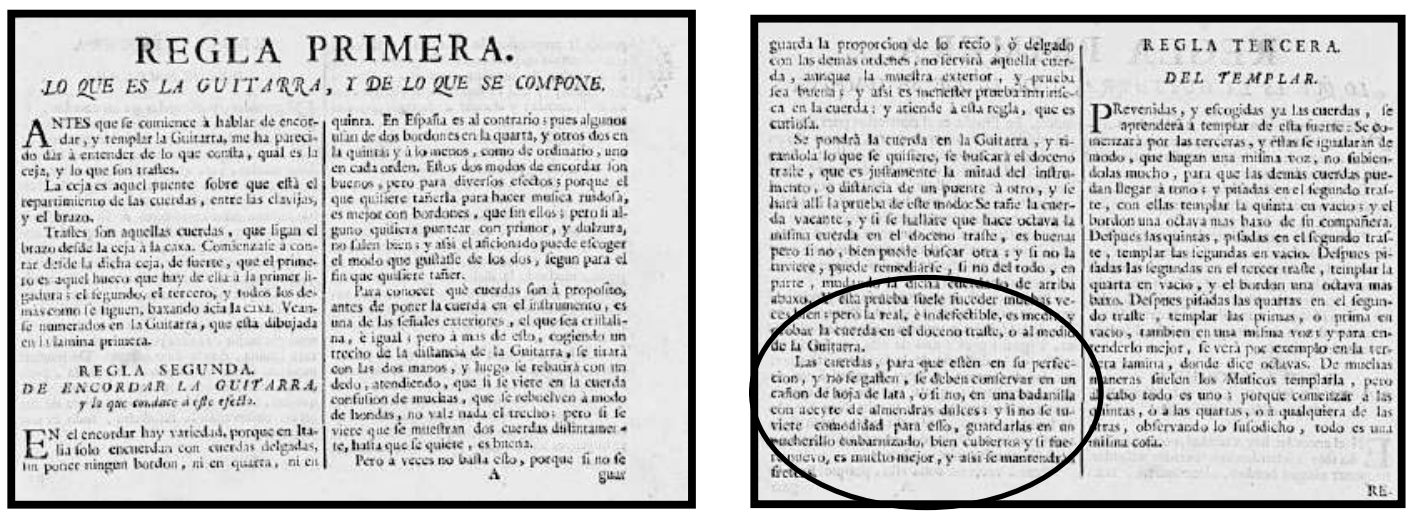

Fig. 17: Regla segunda Pablo Minguet (1754).

La regla tercera Del templar de ambas ediciones de Reglas y Advertencias de Pablo Minguet también está copiada — con variaciones y sin el ejemplo práctico- de la regla segunda bajo el mismo nombre de Gaspar Sanz. Como puede observarse a lo largo de este artículo, Gaspar Sanz es una de las influencias más significativas a la hora de elaborar este cuadernillo sobre la guitarra, tiple y bandola.

No obstante, resulta destacable que esta regla evolucionara y encontrara nueva formulación en Minguet, pues en su época ya se utilizaban los bordones para afinar la guitarra debido a los cambios organológicos que sufrió este instrumento alrededor de $1750^{23}$.

23 Para profundizar en dichas modificaciones, consultar Díaz Soto, R.; Alcaraz Iborra, M. (2009). La guitarra: Historia, organología y repertorio. Alicante: Editorial Club Universitario, pp. 87-91. 
REGLA SEGUNDA DEL TENPLAR.

Revenidas,y efcogidas yà las cuerdas,aprenderàs a templar de efta fuerte : Començaràs por las terceras, y eftas las igualaràs de modo, que hagan vna mifma voz, no fubiendolas mucho, para que las demas cuerdas puedan llegar a tono. Defpues las quintas en vacio, fe igualan con las terceras,piffadas en fegundo trafte. Defpues las fegundas en vacio con las quintas, piffadas tambien en fegundo trafte. Defpues las quartas en vacio con las

las fegundas, piffadas en tercero tralte. Y vitumamente, la prima en vacio, con las quartas pilfadas en fegundo trafte, comolo veràs en el figuiente exemplo.

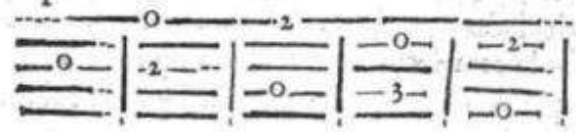

REGLA TERCERA.

DEL TEMPLAR.

$P^{\text {Revenidas, } y \text { efcogidas ya las cuerdas, fe }}$ aprendera a tempiar de efta fuerte : Se coinerzara por las terceras, $y$ éftas fe igualarain de modo, que hagan una mifima voz, no fubiendolas mucho, para que las demàs cuerdas puetantheger a tono; y pifadas en el fegundo trafte, con ex.as templar la quinta en vacio ; y el bordon un. oct.sva mas baxo de fu compañera. Defoue his quintas, pifideren el fegundo trafre, templar las fegnidas en vacty. Defpues pifadas las fegandas en el tercer trance, templar la quarta en vacio, el bordon u.a octava mas baxo. Defpres piradales quants en el fegun-

do trafte, templar las primas, o prima en vacio, tambien en una mifiua voz; y para entenderlo mejor, fe vera por exemplo en la tercera lamina, donde dice octavas. De muchas maneras fuiclen los Muticas templarla, pero al cabo todo es uno ; porque comenzar a las quintas, o a las quarras, o a qualquiera de las otras, obfervando lo fufodicho, todo es una milima cota.

Fig. 18: Comparativa regla tercera (Sanz, 1674 - Minguet, 1754 y 1774).

La regla cuarta Para poner los trastes en su lugar que Pablo Minguet incluye en la primera edición de Reglas y Advertencias es la regla tercera de Gaspar Sanz, aunque sin el ejemplo. En la edición de 1774, Minguet prescinde de ella:

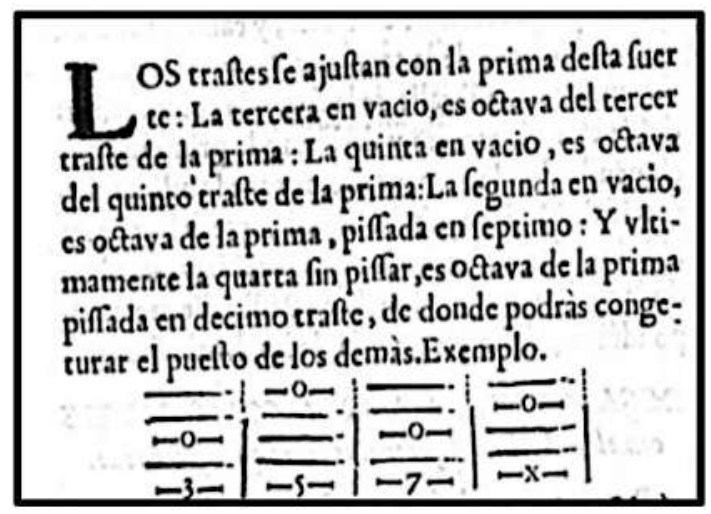

REGLA QUARTA.

PARA PONER LOS TRASTES EN fu lugar.

I OS traftes fe ajuftan con las primas, de efta 1 fuerte: Las terceras en vacio fon octava del tercer trafte de las primas; las quintas en vacio fon octava del quinto trafte de las primas; las fegundas en vacio fon octava de las primas, pifadas en el feptimo trafte; y ultimamente las quartas,fin pifar, fon octava de las primas, pifadas en el decimo rrafte, de donde te podrà congeturar el puefto de los demas. Veale en las octavas, lamina tercera.

Fig. 19: Comparativa regla cuarta (Sanz, 1674 - Minguet, 1754).

Un posible motivo por el cual Pablo Minguet no ofrece la información de los trastes en la reedición de su tratado podría ser que mientras que en el tiempo de publicar la primera edición seguían fabricándose guitarras de trastes móviles "propios de la tradición vibuelística y de la guitarra barroca” (Vargas y Guzmán, 1994, p. XXII), veinte años después — 
Reglas y AdVERTENCIAS Generales de Pablo Minguet (1754 y 1774): Estudio DE SUS

DIFERENTES EDICIONES Y ANÁLISIS DE LAS PAUTAS PARA LA INTERPRETACIÓN DE LA GUITARRA

coincidiendo con la siguiente edición del tratado - ya se utilizaban las guitarras de trastes fijos (con barras metálicas), por lo que no era necesaria dicha explicación por parte del autor.

Una vez explicado cómo poner a punto la guitarra, Minguet enseña en las reglas quinta, sexta y séptima — cuarta, quinta y sexta de la edición de 1774— qué son los puntos y cuál es la disposición de los mismos, tanto naturales como bemolados. Las diferencias entre ediciones de estas pautas son mínimas, limitándose exclusivamente a la adición de pequeñas especificaciones de nomenclaturas o la referencia a láminas ilustrativas concretas.

De la regla octava - y séptima en la segunda edición - con el nombre De cómo con los dichos puntos se pueden formar toda manera de tonos por doce partes diferentes hay que subrayar la enumeración de formas musicales que hace Pablo Minguet y que revelan qué música se interpretaba con la guitarra con mayor asiduidad. Así pues, este autor menciona los pasacalles, paseos, villanos, canarios, gallardas, imposibles, pavanas, fandangos, seguidillas y folías. La divergencia en esta regla entre ambas publicaciones de Reglas y Advertencias reside en que en la primera edición distingue entre folías de procedencia española e italiana y en la reedición no alude al origen de esta forma musical. A la hora de establecer una hipótesis sobre la omisión del origen de las folías es conveniente recordar la reacción de las últimas décadas a las modas italianas y francesa —establecidas en España a lo largo del siglo XVIII - en la que se reivindicó "lo popular y lo tradicional frente a lo extranjerizante" (Martín Moreno, 1985, p. 306). Dicha reacción, denominada majismo, no pasó desapercibida para aquellos viajeros que nos visitaron y pudieron apreciar las costumbres autóctonas, ahora convertidas en la nueva moda ${ }^{24}$.

Tanto la regla novena titulada De cómo las susodichas tonadillas, después de saberlas tañer por las doce partes, se les pueden añadir en cada una de ellas tantas diferencias, como trastes tenga la Guitarra, como la regla décima —octava y novena en la edición de 1774, respectivamente- con el nombre Del modo de sacar las diferencias que se quisieren en todas las doce partes de las susodichas tonadillas están enfocadas al aprendizaje de la ejecución de variaciones. Minguet también explica en sendas normas que las figuras musicales señalan los golpes que se han de dar, "tanto por arriba como por abajo" y, por otro lado, especifica que los números pequeños encima de los grandes se refieren a los trastes en los que se ha de poner el dedo índice. De estas directrices no hay divergencias trascendentales entre publicaciones del tratado.

Hay que indicar que el autor se abstiene de incluir en la edición de 1774 la regla undécima Del modo de acompañar con la Guitarra al Violin, y la bandurria que aparece en la primera edición. Es bien sabido que, tanto en el siglo XVII como al comienzo del siglo XVIII, la guitarra se utilizaba junto al violín y otros instrumentos para acompañar piezas cortas en el teatro. Sin embargo "al surgir la tonadilla escénica como una forma dramática-musical definida, después de 1750, la guitarra desapareció como instrumento acompañante en el escenario, reemplazada por pequeñas orquestas" (Hamilton, 1937, p. 147). Por tanto, la no inclusión de este

\footnotetext{
${ }^{24}$ Antonio Martín Moreno también justifica esta reacción recordando los ideales naturalidad y simplicidad de la Ilustración, que pudieron llevar a las clases populares a no querer imitar las costumbres extranjeras (Martín Moreno, 1985, p. 308)
} 


\section{SAKIRA VENTURA QUINTANA}

apartado en la reedición de Reglas y Advertencias podría justificarse, en primer lugar, con la argumentación expuesta de Mary Neal Hamilton y, en segundo lugar, con el papel solístico que paulatinamente va adquiriendo la guitarra, rol que defenderán décadas más tarde autores como Fernando Fernandiere o el Padre Basilio.

En la regla duodécima de la edición de 1754 — y décima para la segunda ediciónDel modo de tañer el tiple, y como se acompaña con la Guitarra hay una especificación en cuanto a la procedencia de las folías, mientras que esa descripción desaparece veinte años después con la reedición de Reglas y Advertencias, un cambio que hemos visto con anterioridad y que seguirá aparecido en los siguientes cuadernillos independientes del tratado.

Después de haber expuesto normas para aprender a tocar de rasgueado la guitarra, las siguientes reglas son — como su propio nombre indica — para aprender a puntear con este instrumento y el tiple. Este apartado también presenta una estructura favorable para la instrucción, pues antes de adentrarse de lleno en el tema, Minguet describe unas pautas generales sobre el modo de puntear y colocar las manos. Estas directrices no varían demasiado entre ediciones. En la versión de 1774 falta la última observación de la regla cuarta titulada Del trino: "la razón es, porque son mies, ò substenidos, que en la musica corresponde este nombre à los trinos y se señalan con una t'. Ya Gaspar Sanz reconoce en su Instrucción de música sobre la guitarra que no todos los trinos están anotados en la partitura (Sanz, 1674, p. 8), permitiendo así mayor libertad interpretativa a los músicos. Minguet pudo haber comprobado este hecho en el transcurso entre ediciones y por eso prescindió de la especificación en la publicación de 1774. En cualquier caso, afirma que este ornamento se señala con una $t \mathrm{y}$, sin embargo, en todos los ejemplos musicales de su tratado que contienen dicho adorno los anota con una tr salvo en el sexto cuadernillo en el que en las láminas de la disposición de los dedos de la flauta travesera y la flauta dulce la $t$ acompaña a los tonos naturales.

En el apartado Otras advertencias de la reedición, Minguet cita a Santiago de Murcia alegando que, si al lector no le convencen sus propias indicaciones, puede consultar las escalas de este autor. Ciertamente, aparecen redactadas y grabadas en láminas en ambas ediciones del tratado las mencionadas escalas de D. Santiago de Murcia, una de las pocas fuentes que Pablo Minguet referencia en su Reglas y Advertencias.

Este cuadernillo de ambas ediciones del tratado también presenta la pauta Del modo de templar la vandola, y como se tañe con la guitarra. Sorprende que el Diccionario de la Música Labor (Peña, 1954, p. 1536) exponga en su entrada de Pablo Minguet que este autor desconocía la obra de Joan Carles Amat, ya que esta regla sobre la bandola la ha copiado íntegra del capítulo último titulado En que se explica lo modo de templar la vandola $i$ com se ajusta amb la guitarra del tratado Guitarra española y vandola en dos maneras de este autor (Amat, 1596, p. 55). Dado que algunas fuentes como Dirionario Enciclopedico Universale della Musica e dei Musicisti (Basso, 1988, p. 113) exponen como lugar de nacimiento de Minguet la ciudad de Barcelona, no es de extrañar que el editor pudiera traducir dicha parte de la obra de Amat del catalán al castellano sin demasiados inconvenientes: 

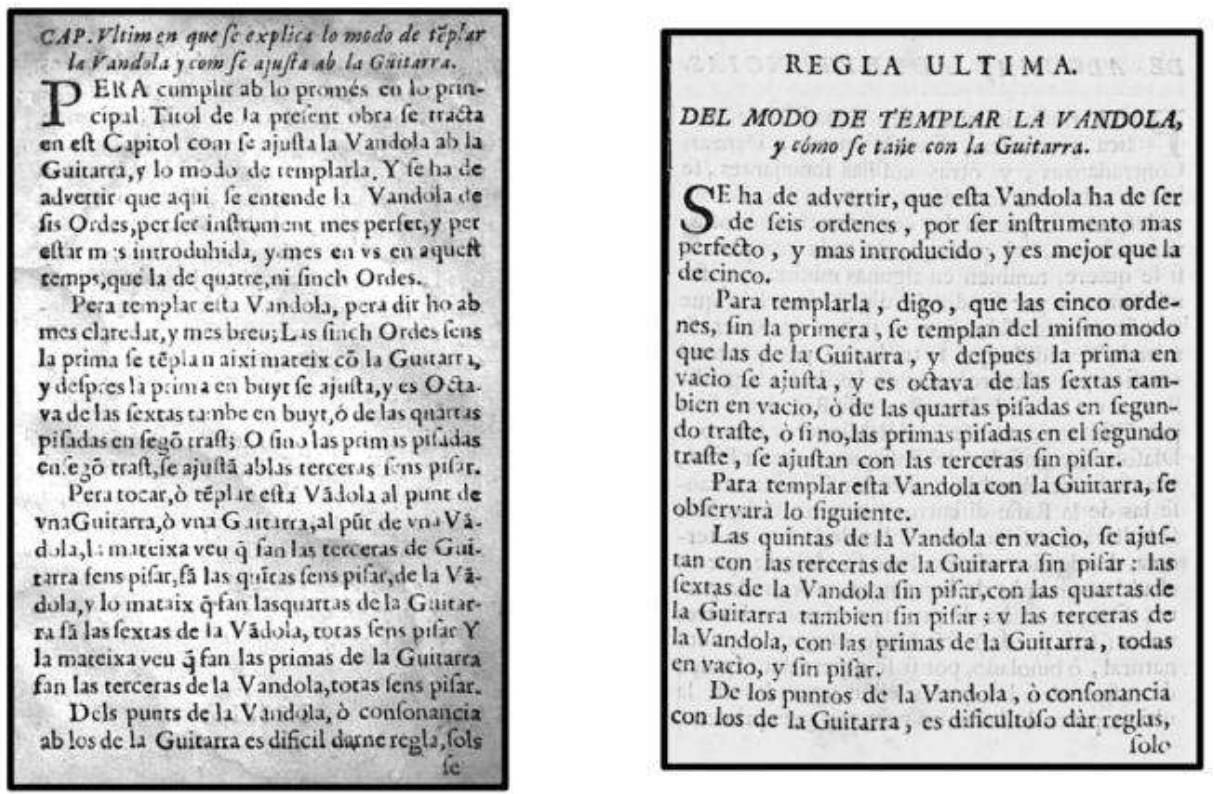

Fig. 20: Comparativa regla última (Amat, 1596 - Minguet, 1754 y 1774).

Es pertinente subrayar que Minguet añade en la primera edición de su Reglas y Advertencias una Explicación de los puntos de la guitarra al estilo castellano, italiano y catalán. Conforme hemos observado a lo largo de este artículo, Pablo Minguet ofrece durante toda la primera publicación una clara diferenciación entre géneros musicales españoles e italianos (como, por ejemplo, en las folías). Sin embargo, en la segunda edición no ofrece ninguna distinción en función de la procedencia de géneros o estilos musicales salvo en algunos ejemplos prácticos que reutiliza de la primera edición. Por lo que corresponde a esta lámina, el autor expone la diferencia de tañer en un estilo u otro. Los puntos de la guitarra al estilo castellano son solo doce, se muestran con números en la parte superior y con ellos no se puede ejecutar "un tañido por los doce tonos". Por otro lado, los puntos al estilo italiano están representados con las letras del abecedario salvo la J, U y W, son doce y sí permiten "ejecutar un tañido por todos los tonos que se quisiere". Finalmente, la mejor opción para Minguet es el estilo catalán, pues tiene todos los puntos y especifica al lado de los números - esta vez en la parte inferior- si son naturales o bemolados.

Lo más sobresaliente de la primera de las láminas que incluye Pablo Minguet en este cuadernillo para la guitarra, tiple y bandola titulada Demostración de los Puntos de la Guitarra, y Tabla que enseña tañer un Sonido con quantas diferencias quisieren es su particular adaptación del Laberinto en la guitarra q enseña un son por 12 partes con quantás diferencias quisieren de Gaspar Sanz (Sanz, 1674, página prima), variación, a su vez, del círculo musical de Joan Carles Amat (Amat, 1596, p. 16). Minguet separa los acordes mayores de los menores y especifica en la parte superior que los números son al estilo castellano, las letras al estilo italiano y los números con $n$ y $b$ (naturales y bemolados) al estilo catalán. Por último, el autor superpone el grabado de una guitarra en la parte de los acordes mayores, si bien aclara que este elemento gráfico no oculta ni priva de ningún tipo de información, puesto que podría entenderse al estudiar el lado opuesto de la tabla: 


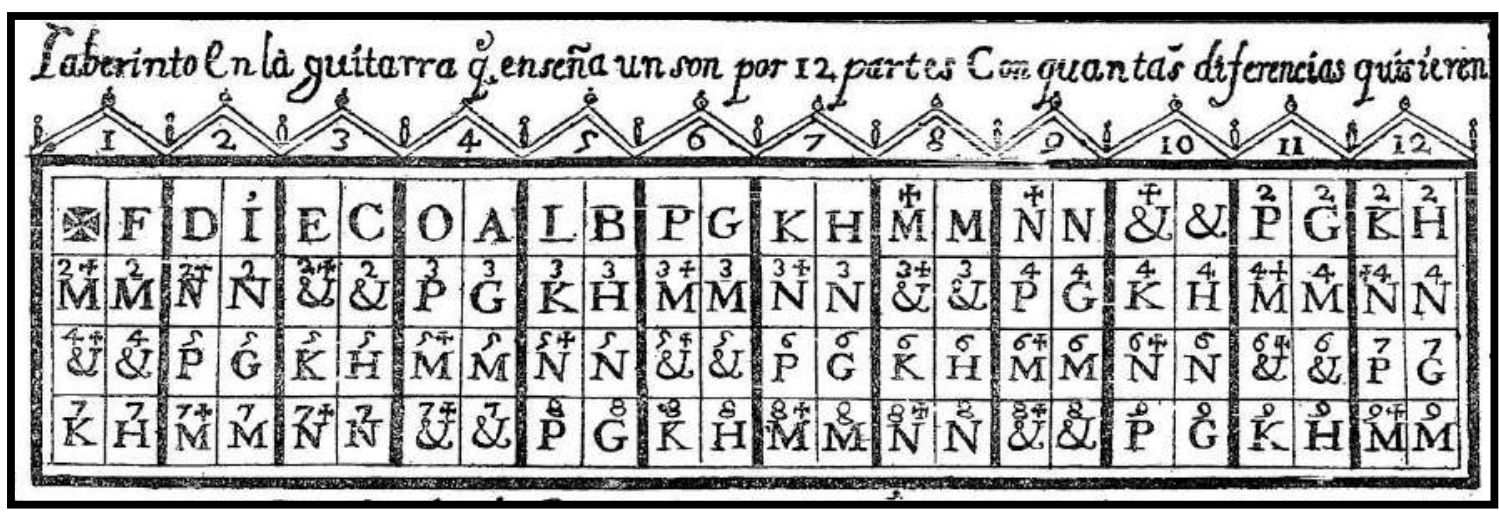

Fig. 21: Laberinto en la guitarra q enseña un son por 12 partes Con quantás diferencias quisieren (Gaspar Sanz).

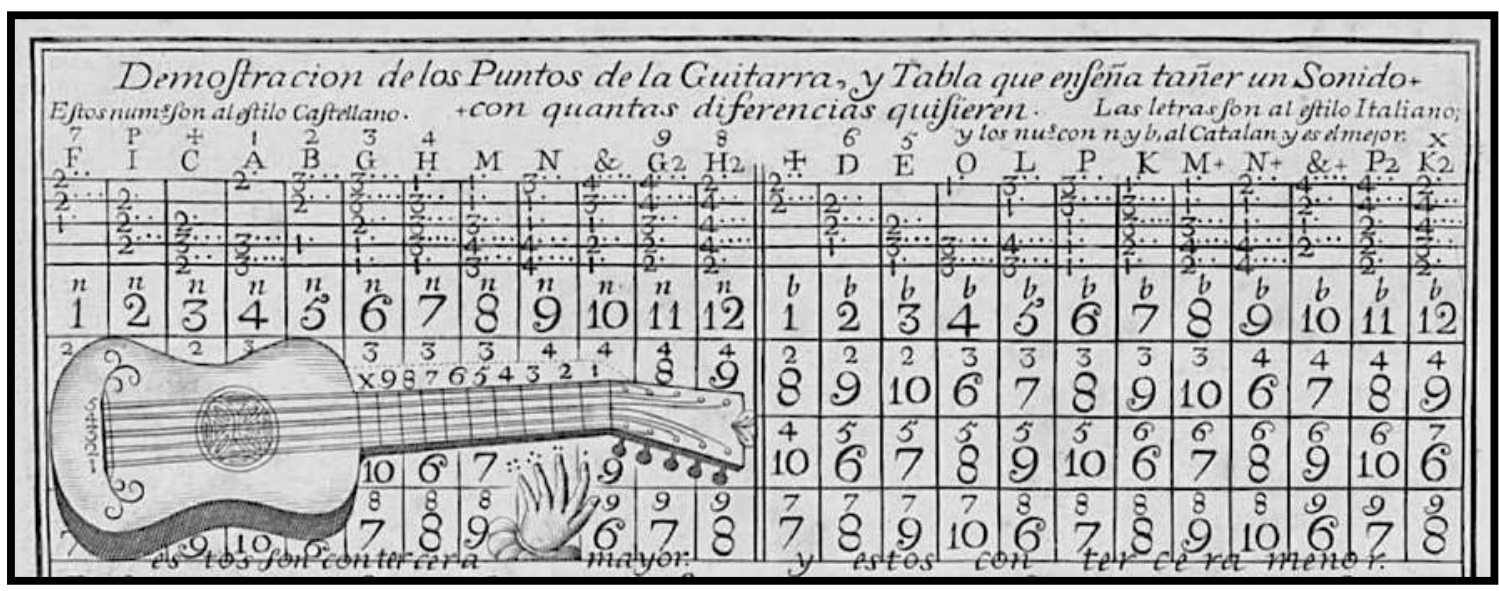

Fig. 22: Demostracion de los Puntos de la Guitarra, y Tabla que enseña tañer un sonido con quantas diferencias quisieren (Pablo Minguet)

En la siguiente lámina, titulada Demonstracion de los Puntos de la Guitarra, para saberlos executar muy fácilmente Sin maestro, Minguet enseña la posición de los dedos a la manera de Gaspar Sanz (Sanz, 1674, p. 13) —adquirida a su vez también de Joan Carles Amat (Amat, 1596, pp. 44 y 45) — esto es, los dedos que llevan un anillo no pisan ninguna cuerda y los puntos marcados en el mástil indican que se han de pisar las cuerdas con las puntas o yemas de los dedos:

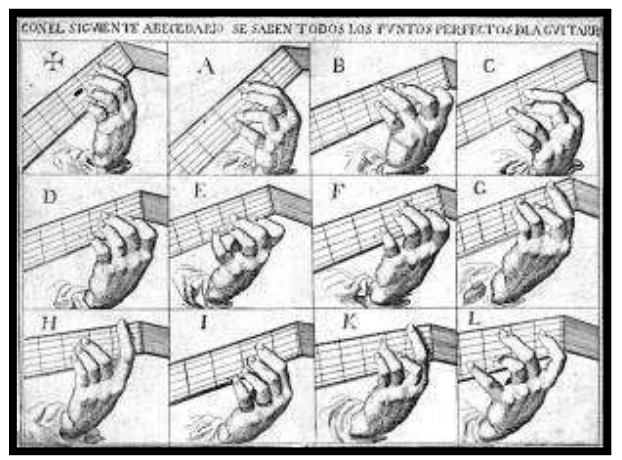

Fig. 23: Con el siguiente abecedario se saben todos los puntos perfectos de la guitarra (Gaspar Sanz). 
Reglas y AdVERTENCIAs Generales de PABlo Minguet (1754 y 1774): EsTUdio De SUS DIFERENTES EDICIONES Y ANÁLISIS DE LAS PAUTAS PARA LA INTERPRETACIÓN DE LA GUITARRA

En la reedición de 1774 podemos observar dos pequeñas aclaraciones que en la publicación de 1754 no aparecen. En primer lugar, en la posición 5,b, dice así: "en lugar deste bay el 7 y ceja al $3^{\circ}$ traste". En segundo lugar, en la posición 10,b. se aprecia lo siguiente: "el n 7 baciendo ceja al $4^{\circ}$ traste":
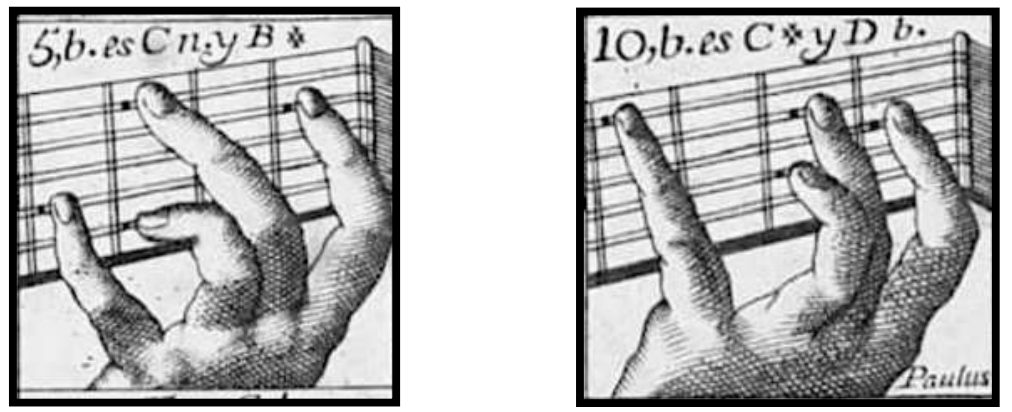

Fig. 24: Nueva Demonstracion de los Puntos de la Guitarra (1754).

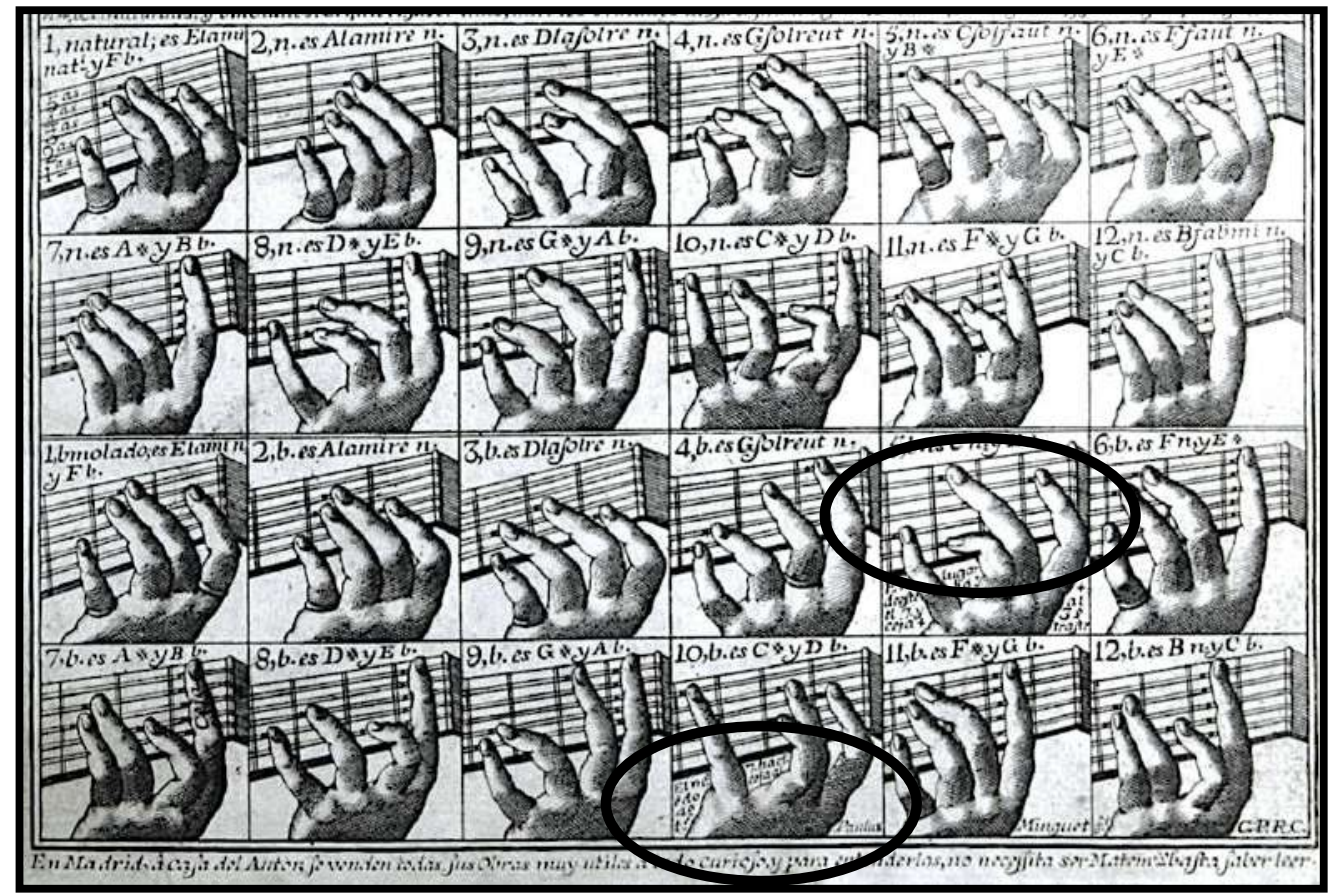

Fig. 25: Nueva Demonstracion de los Puntos de la Guitarra (1774).

La lámina que se muestra a continuación — sin modificaciones de una edición a la siguiente - incluye diversos ejemplos musicales. Los primeros son La Jota por el Cruzado y Fandango por Patilla, entendiéndose el cruqado como "el nombre de la postura de un acorde en la guitarra que difería según el sistema de cifra adoptado por unos y otros vihuelistas" (Pedrell, 1894, p. 124) y por patilla como "cierta postura (acorde) de la mano izquierda en los trastes" (Pedrell, 1894, p. 353): 


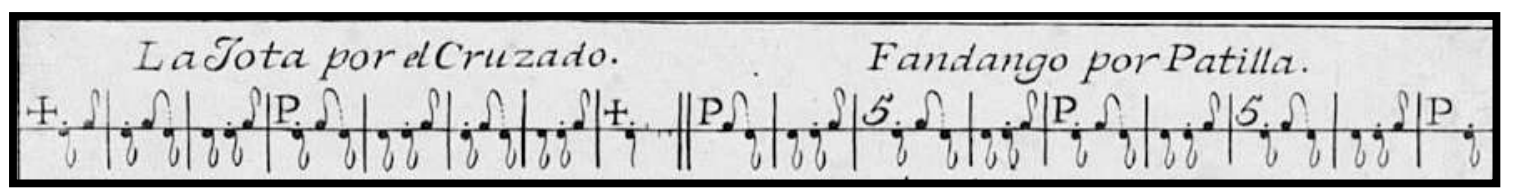

Fig. 26: Jota por cruzado y Fandango por patilla (1754).

Así como he comentado anteriormente, la especificación de la procedencia de ciertos géneros musicales desaparece en la reedición del tratado. Sin embargo, Minguet reutiliza en esta ocasión la presente lámina sin cambios, por lo que los ejemplos de folías van a estar acompañadas del lugar de origen (España e Italia). Por otro lado, el autor también nos ofrece aquí los puntos en los estilos castellano, italiano y catalán:

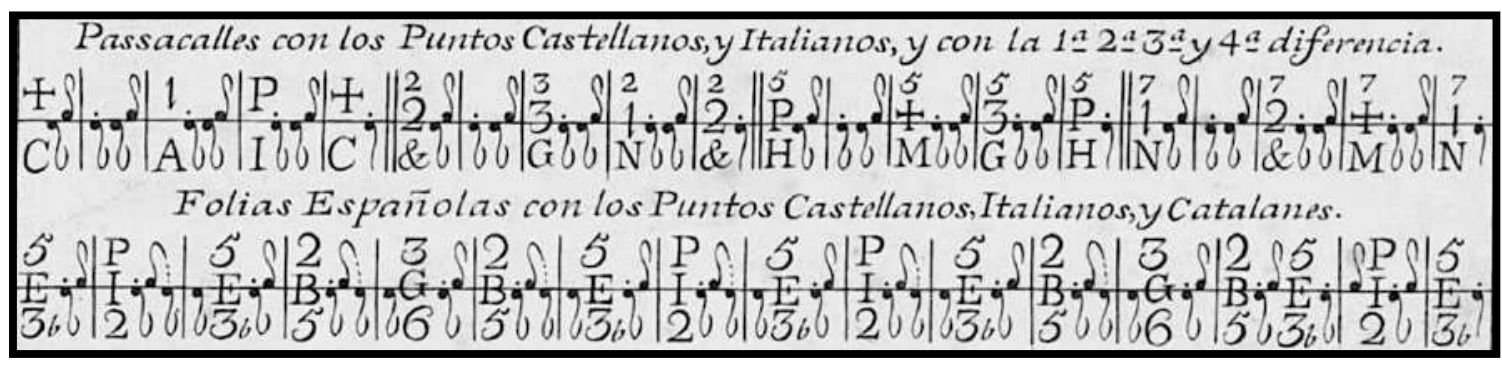

Fig. 27: Pasacalles con los Puntos Castellano, y Italianos (1754).

Otro de los aspectos más significativos de esta lámina es su elaborado grabado en el "que demuestra los Signos, y Voces de la Musica, que corresponden a las cuerdas y trastes de la Guitarra":

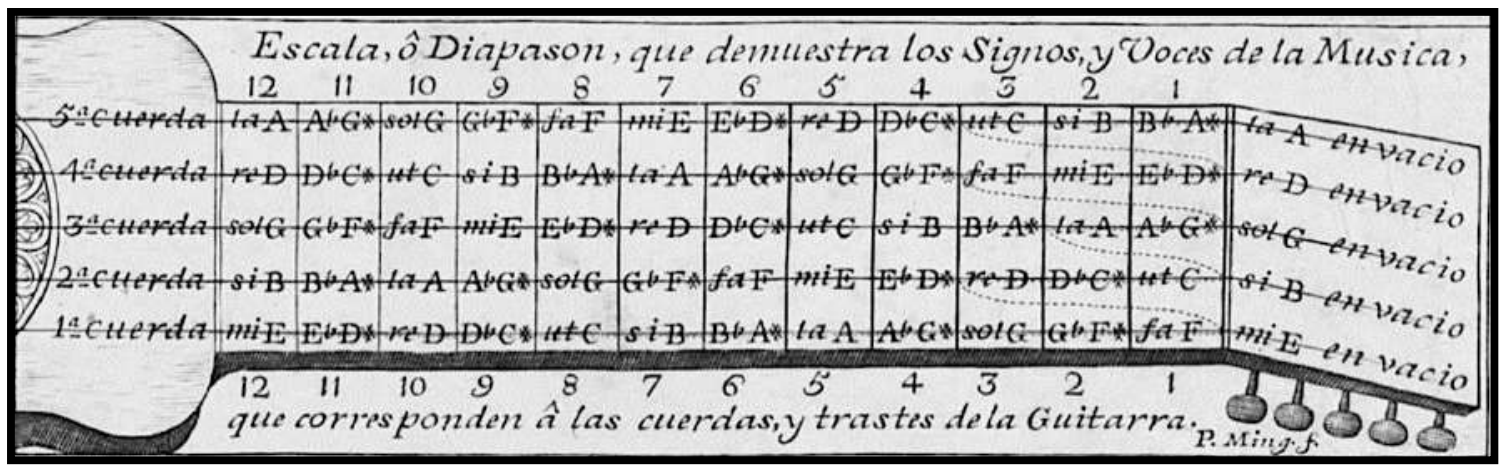

Fig. 28: Escala, ô Diapason, que demuestra los Signos, y Voces de la Musica (1754 y 1774).

Consciente de la evolución que se ha dado en el ámbito de la teoría y práctica musical en los veinte años de diferencia de una edición a la sucesiva de Reglas y Advertencias, Minguet adapta las dos láminas que voy a analizar seguidamente para ofrecer una enseñanza actualizada — sin pautas anticuadas y en desuso- que garantice una interpretación de calidad y acorde a la estética imperante del momento. Así pues, la lámina Breve resumen de los Rudimentos mas necessarios para aprender la Musica presenta considerables cambios o adiciones 
REglas y AdVERTENCIAS GENERALES DE PABLO MINGUET (1754 Y 1774): EsTUdio DE SUS DIFERENTES EDICIONES Y ANÁLISIS DE LAS PAUTAS PARA LA INTERPRETACIÓN DE LA GUITARRA

en la edición de 1774 respecto a la anterior. Para empezar, el autor añade el nombre de las notas y el Nuevo estilo de solfear sin ninguna mutanza al subir, y baxar.

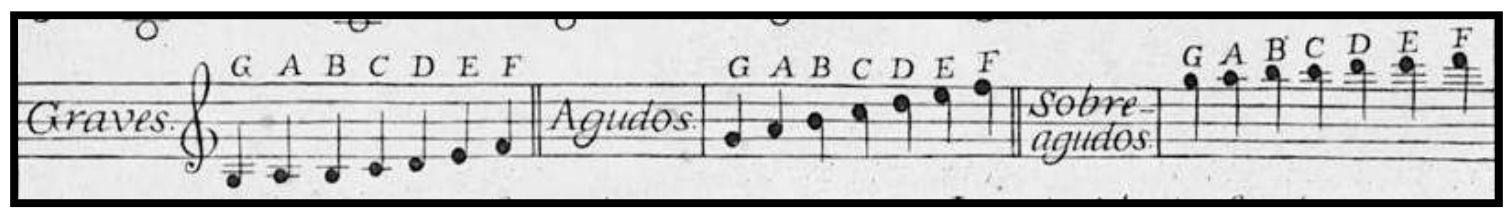

Fig. 29: Breve resumen de los Rudimentos mas necessarios para aprender la Musica (1754).

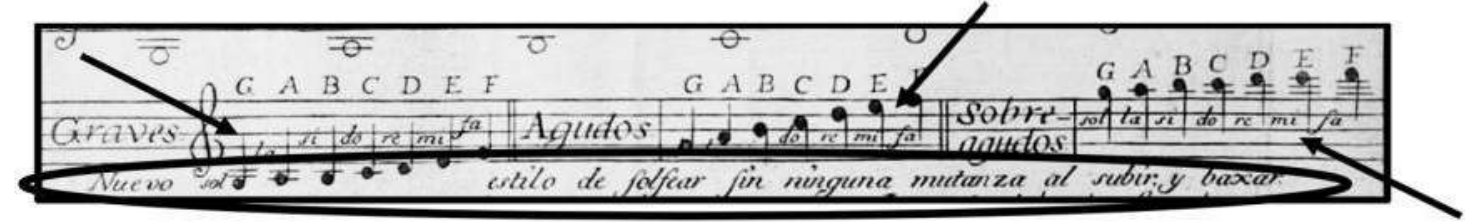

Fig. 30: Breve resumen de los Rudimentos mas necessarios para aprender la Musica (1774).

El siguiente cambio en esta lámina aparece en las Apoyaturas y en las Pausas, ô Señales quando el Musico se debe parar, por quanto el valor del Señal, cuyas grafías son ligeramente diferentes en la segunda edición y el autor incluye más símbolos asociados a nuevas figuras de mensuración, más breves que en la primera versión:
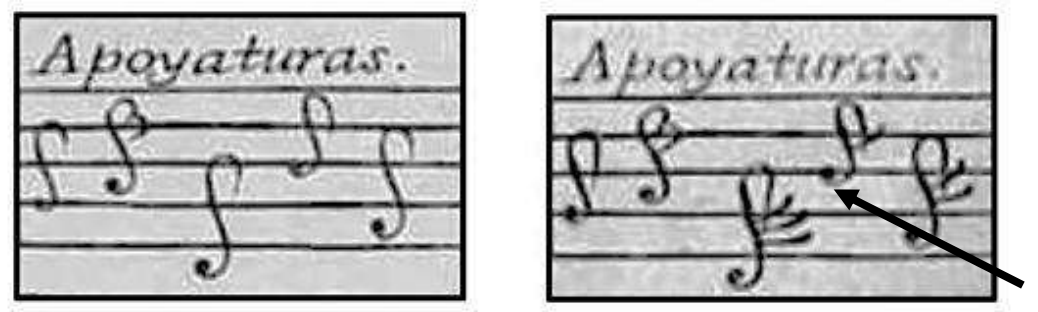

Fig. 31: Apoyaturas (1754 y 1774).

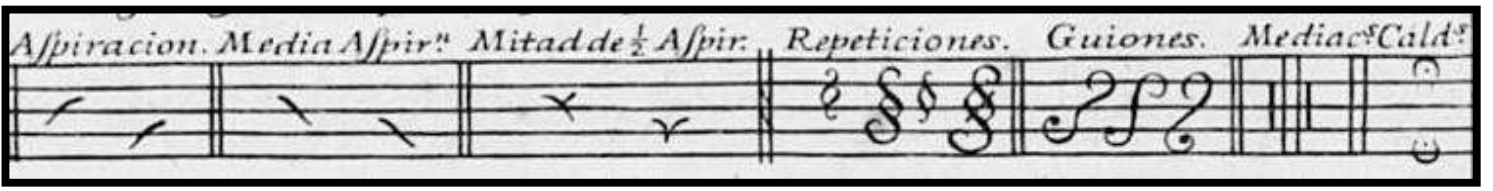

Fig. 32: Pausas, ô Señales quando el Musico se debe parar, por quanto el valor del Señal (1754). 


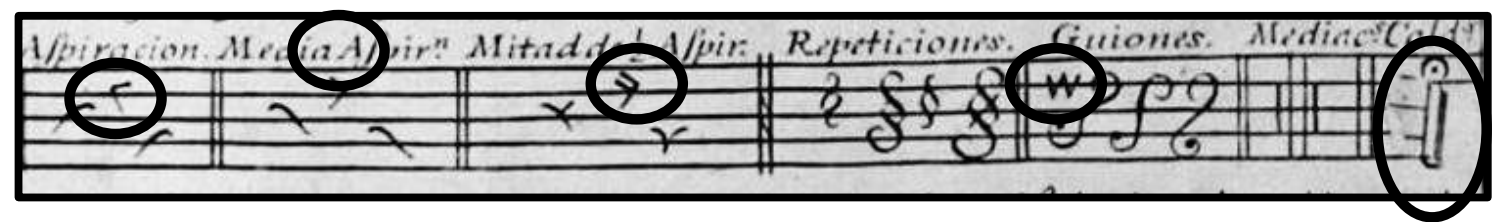

Fig. 33: Pausas, ô Señales quando el Musico se debe parar, por quanto el valor del Señal (1774).

En este mismo sentido, en el apartado Tiempos, ò compasses de sendas ediciones especifica el desuso en que habían caído algunos valores de duración, comentario motivado quizás por su interés en ofrecer conocimiento actual sobre la moderna escritura del instrumento:

Noteffe que el B mol antepuefto a la Nota mengua la mitadiel Subftenido crece la mitad yel B quadro buelve la

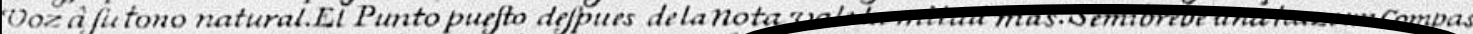

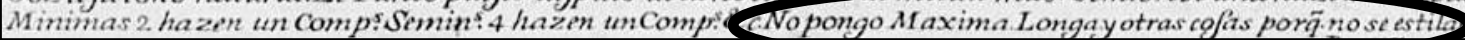

Fig. 34: Tiempos, ò compasses (1754 y 1774).

La lámina siguiente titulada Escala de Gsolreut por la Guitarra de la edición de 1774 contiene, por un lado, títulos más extensos en los que especifica que las folías se tocarán de punteado y las seguidillas de rasgueado. Es de suponer que como el autor había publicado tratados de danza, tanto anteriores a 1754 como durante los veinte años de diferencia entre ediciones, estuviera sobradamente capacitado para ser más preciso en sus indicaciones, tanto en estos ejemplos como en otros de los siguientes cuadernillos individuales de Reglas $y$ Advertencias. Por otro lado, añade los golpes de rasgueado de las seguidillas:

- Folias Españolas, y fáciles para que el aficionado sepa entender, y executar los Tañidos de punteado.

- Seguidillas fáciles y nuevas. Los num ${ }^{s}$ del punteado tamb" sirven para exec" los golpes de rasgueado.

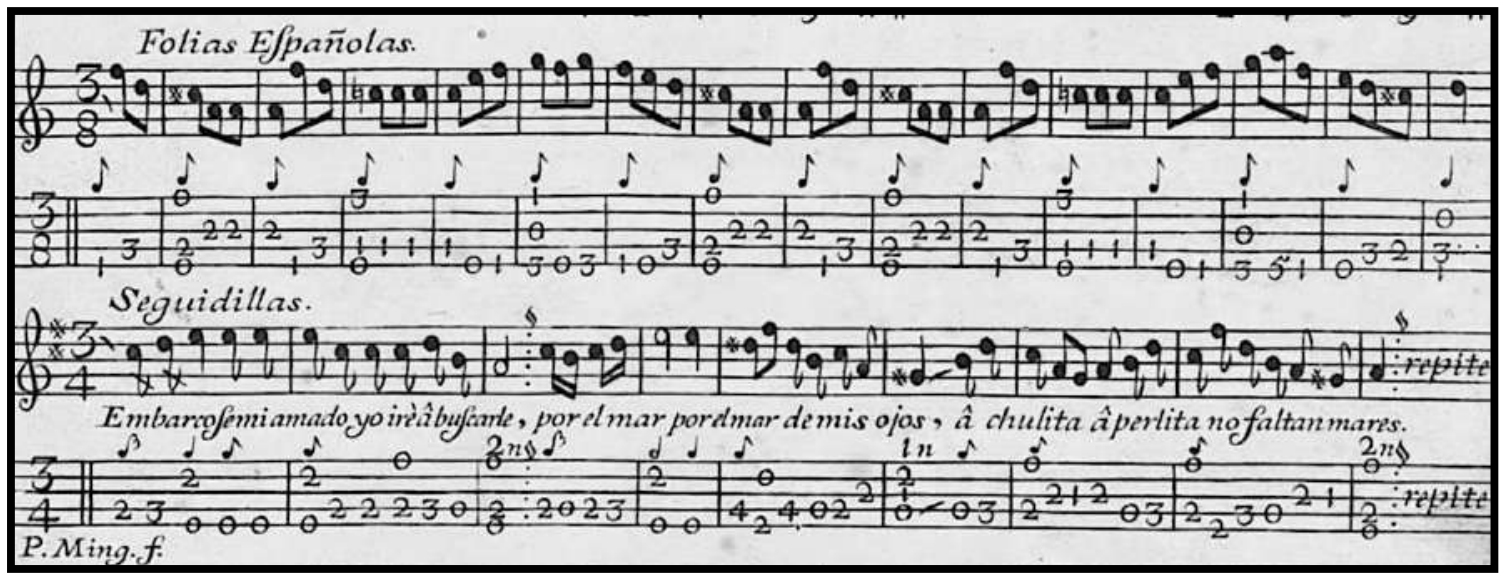

Fig. 35: Folias Españolas y Seguidillas (1754). 


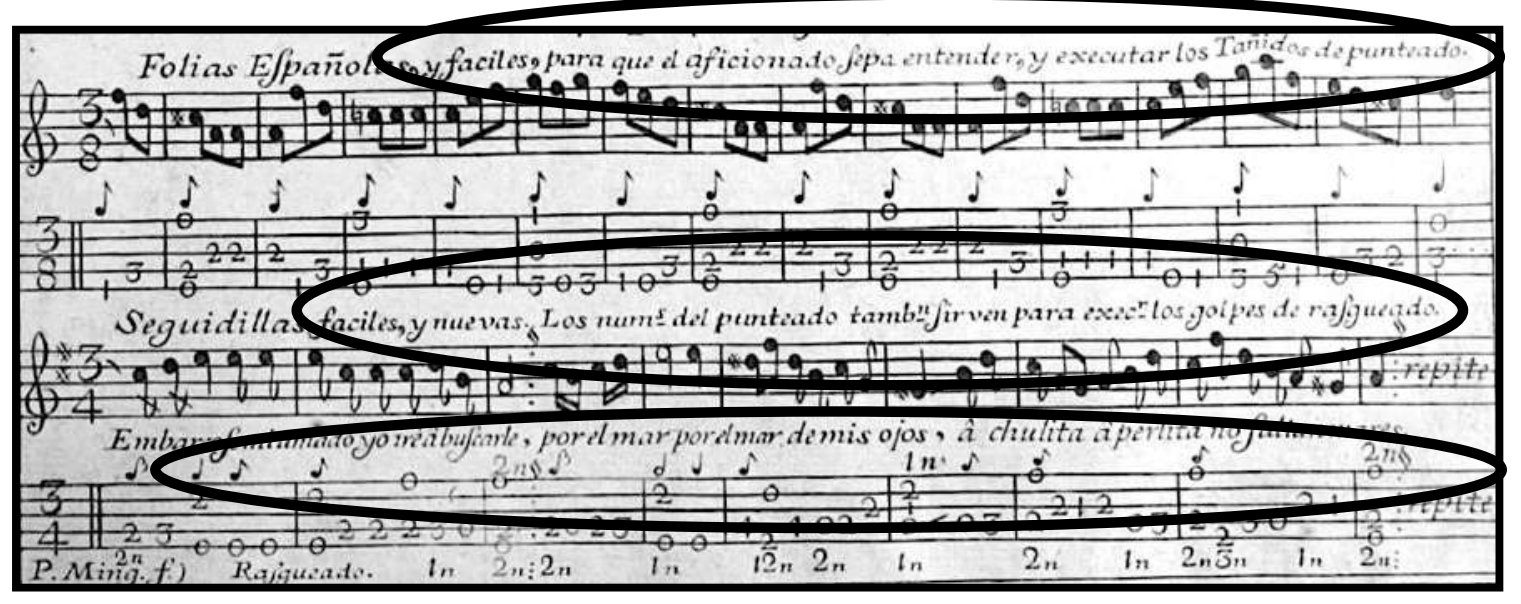

Fig. 36: Folias Españolas y Seguidillas (1774).

En ambas ediciones de este cuadernillo incorpora un tipo de danza ( $L a$ Rafa) en música y cifra que hace un siglo "era desconocida" — a día de hoy todavía no se ha estudiado desde el ámbito académico- y que "presenta analogías con las modiñas portuguesas" (Mitjana, 1936, p. 296):

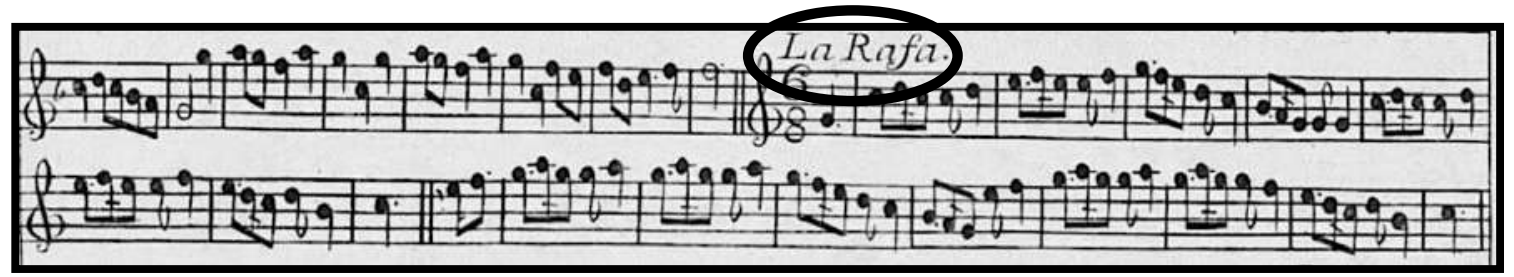

Fig. 37: La Rafa (1754).

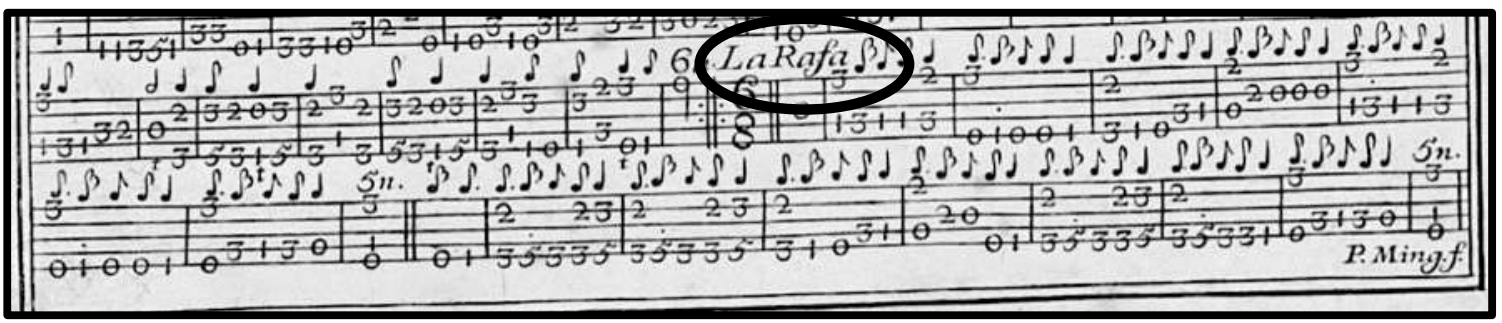

Fig. 38: La Rafa (1754).

A colación de sus ejemplos musicales de danzas, la última lámina que aparece en este cuadernillo de la edición de 1774 no está incluida en la primera publicación de Reglas y Advertencias. Su título versa así: Contradan nuevas, y alegres, dedicad â las cinco letras vocales para ponerlas los nomb que quisin. Conviene subrayar que las contradanzas - tipo de danza francesa

25 “... and an example of an ancient dance, a rafa, now unknown" (Hamilton, 1937, p. 150). 
más popular del siglo XVIII- es un género que no está contemplado por autores anteriores a Pablo Minguet como Gaspar Sanz, Santiago de Murcia o Lucas Ruíz de Ribayaz. Un aspecto interesante de esta lámina es la siguiente indicación de Minguet sobre cuándo es más propicio interpretar ciertas danzas: "Las violentas son para el Invierno, las algo alegres en las Prim ${ }^{\text {ras }}$ y las faciles el Verano por no calorarse".

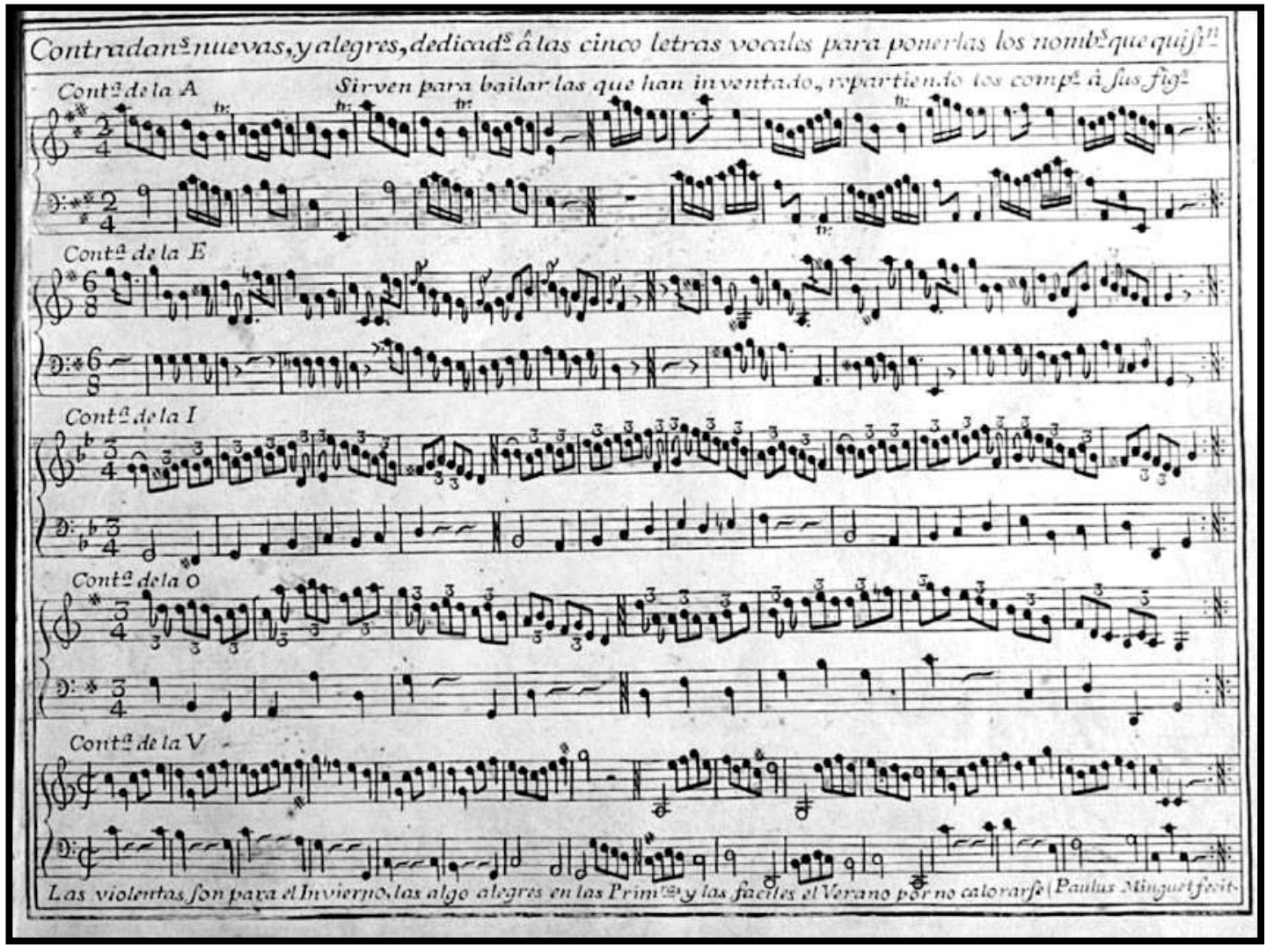

Fig. 39: Contradan nuevas, y alegres, dedicad â las cinco letras vocales para ponerlas los nombs que quisin (1774).

\section{CONCLUSIONES}

Además de los posibles incentivos empresariales que pudiera tener para realizar ediciones de temas tan diversos, después del estudio de ambas ediciones del tratado Reglas y Advertencias Generales podemos aventurar que Pablo Minguet fue un autor preocupado por compilar y compartir información, inquietud tan propia del Siglo de las Luces. Ofreció unas directrices concretas para la instrucción de los instrumentos que ofertaba en su tratado y, especialmente, reglas actualizadas en función de la evolución que se dio tanto en el ámbito de la teoría musical como en los métodos pedagógicos de aprendizaje.

El cuadernillo que sufrió más modificaciones entre ambas versiones fue el de la guitarra, tiple y bandola, pudiéndose observar cómo prescinde de ciertas reglas que en el transcurso de los veinte años entre sendas ediciones ya se habían quedado obsoletas. Es un 
Reglas y AdVERTENCIAS Generales de Pablo Minguet (1754 y 1774): Estudio DE SUS

DIFERENTES EDICIONES Y ANÁLISIS DE LAS PAUTAS PARA LA INTERPRETACIÓN DE LA GUITARRA

método para guitarra que no solo servía para conocer el instrumento y aprender a tocarlo, sino que enseñaba al aprendiz qué formas musicales estaban en boga y cómo interpretarlas.

Respecto a las fuentes consultadas — pero no todas citadas-, Pablo Minguet estudió a las personalidades más importantes de la pedagogía instrumental dedicada a la guitarra de los siglos XVII y XVIII con el fin de poder realizar su tratado Reglas y Advertencias. Entre dichas fuentes destaca la figura de Gaspar Sanz, la influencia de Lucas Ruiz de Ribayaz y de Santiago de Murcia y el legado de Joan Carles Amat.

El conocimiento de la tratadística instrumental se revela, por tanto, como condición imprescindible para la interpretación del repertorio coetáneo. La restitución sonora del repertorio histórico exige, como punto de partida, el conocimiento del contexto y de los parámetros que guiaron la composición de la obra. De este modo, se plantea como nueva vía de estudio la aplicación práctica de los conocimientos expuestos en el tratado Reglas y Advertencias Generales de Pablo Minguet, tanto a la pedagogía actual de la guitarra como a la interpretación del repertorio dieciochesco.

\section{BIBLIOGRAFÍA}

Abreu, A. (1799). Escuela para tocar con perfección la guitarra. Salamanca: Imprenta de la calle del Prior.

Amat, J. C. (1596). Guitarra española y vandola en dos maneras de guitarra, castellana y cathalana de cinco órdenes, la qual enseña de templar y tañer rasgado. Barcelona: Gabriel Bro.

Basso, A. (1988). Dizionario Enciclopedico Universale della Musica e dei Musicisti, vol. 5. Torino: UTET.

Cruz Brocarte, A. (1707). Medula de la música teórica cuya inspección manifiesta claramente la ejecución de la práctica en división de cuatro discursos. Salamanca.

Díaz Soto, R. \& Alcaraz Iborra, M. (2009). La guitarra: Historia, organología y repertorio. Alicante: Editorial Club Universitario.

Fernandiere, F. (1799). Arte de tocar la guitarra española por música. Madrid, Pantaleón Aznar.

García Rubio, J. M. (1799). Arte, reglas y escalas armónicas para aprehender a templar y puntear la Guitarra Española de seis órdenes según el estilo moderno.

Grimberg, C. (1973). Historia Universal: El siglo de la Ilustración, 9. Barcelona: Daimon. 


\section{SAKIRA VENTURA QUINTANA}

Guzmán, J. (1709). Curiosidades del cantollano, sacadas de las obras del Reverendo don Pedro Cerone de Bérgamo y de otros autores. Madrid: Imprenta de Música.

Hamilton, M. N. (1937). Music in Eighteenth century Spain. Nueva York: Da Capo Press.

Hochuli, J. \& Kinross, R. (2005). El diseño de libros. Barcelona: Campgràfic Editoris.

León Tello, F. J. (1974). Teoría española de la música de los siglos XVII y XVIII. Madrid: Instituto Español de Musicología, CSIC.

Leza, J. M. (2014). Historia de la música en España e Hispanoamérica: la música en el siglo XVIII, $1^{a}$ ed. Madrid: Fondo de Cultura Económica.

Martín Moreno, A. (1985). Historia de la música española: siglo XVIII, 1. a ed. Madrid: Alianza Editorial.

Michel, F. (1967). Enciclopedia Salvat de la música, vol. 3. Barcelona: Salvat.

Minguet, P. (1754). Reglas y Advertencias Generales que enseñan el modo de tañer todos los instrumentos mejores, y mas usuales, como son la guitarra, tiple, vandola, Cythara, Clavicordio, Organo, Harpa, Psalterio, Bandurria, Violin, Flauta Travesera, Flauta Dulce, y la Flautilla. Madrid: Joaquín Ibarra.

Minguet, P. (1755). El noble arte de danzar a la francesa, y española adornado con LX laminas finas, que enseñan el modo de hacer todos los passos de las danzas de Corte. Madrid: Pablo Minguet.

Minguet, P. (1764). Breve tratado de los pasos del danzar a la española. Madrid: Pablo Minguet.

Minguet, P. (1774). Reglas y Advertencias Generales que enseñan el modo de tañer todos los instrumentos mejores, y mas usuales, como son la guitarra, tiple, vandola, Cythara, Clavicordio, Organo, Harpa, Psalterio, Bandurria, Violin, Flauta Travesera, Flauta Dulce, y la Flautilla. Madrid: Pablo Minguet.

Mitjana, R. (1993). Historia de la música en España. Madrid: Ministerio de cultura.

Moretti, F. (1799). Principios para tocar la guitarra de seis órdenes, precedido de los elementos generales de la música. Madrid: Gabriel de Sancha.

Nassarre, P. (1724). Escuela música según la práctica moderna. Zaragoza: Herederos de Diego de Larumbe.

Pedrell, F. (1894). Diccionario técnico de la música, vol. 1. Barcelona: Victor Berdós. 
Reglas y AdVERTENCIAS Generales de Pablo Minguet (1754 y 1774): Estudio DE SUS DIFERENTES EDICIONES Y ANÁLISIS DE LAS PAUTAS PARA LA INTERPRETACIÓN DE LA GUITARRA

Peña, J. \& Anglés, H. (1954). Diccionario de la música Labor, vol. 2. Barcelona: Editorial Labor.

Pérez Martínez, V. (1799). Prontuario del canto llano gregoriano. Madrid: Pedro Julián Pereyra.

Ramos Altamira, I. (2005). Historia de la guitarra y de los guitarristas españoles. Alicante: Club Universitario.

Ruíz de Ribayaz, L. (1677). Lu₹y y norte musical para caminar por las cifras de la guitarra española. Madrid: Melchor Álvarez.

Sanhuesa, M. (2000). Minguet, Pablo. En E. Casares (Dir.). Diccionario de la música española e hispanoamericana, vol. 7 (pp. 588-592). Madrid: SGAE.

Sanz, G. (1674). Instrucción de música sobre la guitarra española; y método de sus primeros rudimentos hasta tañerla con destreza. Zaragoza: Herederos de Diego Dormer.

Siemens, L. (1988). Los violinistas compositores en la corte española durante el período central del siglo XVIII. Revista de Musicología, vol. 11, nº 3, pp. 657-739, 741-765.

Ulloa, P. (1717). Música universal o principios universales de la música. Madrid: Bernardo Peralta.

Vargas y Guzmán, J. A. (1799). Explicación de la guitarra de rasgueado, punteado y haciendo la parte de el baxo repartida en tres tratados por su orden. Cádiz. [Edición facsímil de la original: Medina Álvarez, Á. (Ed.) (1994). Explicación de la guitarra de rasgueado, punteado y haciendo la parte de el baxo repartida en tres tratados por su orden. Granada: Centro de Documentación Musical].

Vera, A. (2008). Santiago de Murcia (1673-1739): new contributions on his life and work. Early Music, vol. 36, nº 4, pp. 597-608.

Fecha de recepción: 23/11/2019

Fecha de aceptación: 12/01/2020 